\title{
Enfraquecimento e perda de colônias de abelhas no Brasil: há casos de CCD?
}

\author{
Carmen Sílvia Soares Pires ${ }^{(1)}$, Fábia de Mello Pereira(2), Maria Teresa do Rêgo Lopes ${ }^{(2)}$, \\ Roberta Cornélio Ferreira Nocelli ${ }^{(3)}$, Osmar Malaspina ${ }^{(4)}$, Jeffery Stuart Pettis ${ }^{(5)}$ e Érica Weinstein Teixeira ${ }^{(6)}$
}

\begin{abstract}
(1)Embrapa Recursos Genéticos e Biotecnologia, Parque Estação Biológica, Avenida W5 Norte (Final), Caixa Postal 02372, CEP 70770-917 Brasília, DF, Brasil. E-mail: carmen.pires@embrapa.br (2)Embrapa Meio-Norte, Avenida Duque de Caxias, no 5.650, Buenos Aires, Caixa Postal 001, CEP 64006-220 Teresina, PI, Brasil. E-mail: fabia.pereira@embrapa.br, maria-teresa.lopes@embrapa. br (3)Universidade Federal de São Carlos, Departamento de Ciências da Natureza, Matemática e Educação, Rodovia Anhanguera, Km 174, CEP 13600-970 Araras, SP, Brasil. E-mail: roberta@cca.ufscar.br (4)Universidade Estadual Paulista, Centro de Estudos de Insetos Sociais, Departamento de Biologia, Instituto de Biociências, Avenida 24, № 1.515, Bela Vista, CEP 13506-900 Rio Claro, SP, Brasil. E-mail: malaspin@rc.unesp.br ${ }^{(5)}$ United States Department of Agriculture, Agricultural Research Service, Bee Research Laboratory, Bldg. 306 BARC-E, 10300 Baltimore Avenue, 20705 Beltsville, Maryland, Estados Unidos. E-mail: Jeff.Pettis@ars.usda.gov ${ }^{\left({ }^{6}\right)}$ Agência Paulista de Tecnologia dos Agronegócios, SAA-SP, Avenida Professor Manoel Cesar Ribeiro, № 1.920, CEP 12400-970, Pindamonhangaba, SP, Brasil. E-mail: erica@apta.sp.gov.br
\end{abstract}

Resumo - Nas últimas décadas, o declínio de populações de abelhas silvestres e o colapso de colônias de Apis mellifera têm preocupado pesquisadores e apicultores. O objetivo deste artigo de revisão foi compilar alguns dos estudos mais relevantes relacionados às possíveis causas desses problemas - como nutrição, manejo, patógenos, parasitas e efeitos de agrotóxicos -, além de apresentar um breve histórico da síndrome "colony collapse disorder" (CCD) nos Estados Unidos e na Europa. Abordaram-se com mais detalhes os estudos desenvolvidos no Brasil, principalmente sobre agrotóxicos utilizados na agricultura e patógenos e parasitas que acometem as colônias de A. mellifera africanizada. Casos de enfraquecimento, declínio e colapso têm sido registrados, principalmente nos estados de São Paulo e Santa Catarina, que somam grandes perdas. Resultados das ocorrências analisadas indicaram que as mortalidades em massa registradas no Brasil não estavam associadas a patógenos ou a parasitas. Somente dois casos com características semelhantes às descritas para CCD foram registrados, porém sem causas definidas. Para que se conheçam as causas de enfraquecimentos e perdas de colônias de abelhas, é urgente a implementação de programas oficiais de levantamento sistemático da sanidade apícola, associados a pesquisas com foco nas avaliações dos possíveis impactos da fragmentação de habitats e das práticas agrícolas sobre as comunidades de abelhas.

Termos para indexação: Apis mellifera, abelha africanizada, distúrbio do colapso das colônias, nutrição de abelhas, patologia apícola, polinização.

\section{Weakness and collapse of bee colonies in Brazil: are there cases of CCD?}

\begin{abstract}
In the last decades, the decline of wild bee populations and the collapse of Apis mellifera colonies have concerned researchers and beekeepers. The objective of this review was to compile some of the most relevant studies related to the possible causes of these problems - such as nutrition, management, pathogens, parasites, and the effects of pesticides -, besides presenting a brief history of the colony collapse disorder syndrome (CCD) in the United States and Europe. The studies developed in Brazil were presented in more detail, mainly those on pesticides used in agriculture and on pathogens and parasites that attack the colonies of Africanized A. mellifera. Cases of weakening, decline, and collapse have been recorded in Brazil, mainly in the states of São Paulo and Santa Catarina, which add up to great losses. Results of the analyzed occurrences indicated that the recorded mass mortalities were not associated with pathogens or parasites. Only two cases with characteristics similar to those described for CCD were recorded, but without defined causes. In order to know the causes of the weakening and collapses of colonies, the implementation of official programs is urgent for the systematic survey of bee health, associated with research focusing on assessments of possible impacts of habitat fragmentation and agricultural practices on bee communities.
\end{abstract}

Index terms: Apis mellifera, Africanized honey bees, colony collapse disorder, bee nutrition, honey bee health, pollination.

\section{Introdução}

Cerca de $70 \%$ das plantas cultivadas, que são utilizadas diretamente para o consumo humano, têm aumento de produção em consequência da polinização promovida por animais, principalmente abelhas (Klein et al., 2007). Das 141 espécies de plantas cultivadas

Pesq. agropec. bras., Brasília, v.51, n.5, p.422-442, maio 2016

DOI: 10.1590/S0100-204X2016000500003 
no Brasil - para uso na alimentação humana, produção animal, biodiesel e fibras -, aproximadamente $60 \%$ (85 espécies) dependem em certo grau da polinização animal (Giannini et al., 2015a). Estima-se que o valor econômico da polinização promovida por insetos corresponde a 9,5\% do valor total da produção agrícola mundial, considerando-se a produção agrícola de 2005 de 100 culturas usadas diretamente para alimentação humana (Gallai et al., 2009). Levando-se em conta a produção agrícola brasileira de 2012, estimou-se o valor econômico da polinização para 44 culturas, que apresentam ganhos variados com a polinização animal, em aproximadamente $30 \%$ da produção total de 45 bilhões de dólares (Giannini et al., 2015a).

Os serviços de polinização nas áreas agrícolas dependem tanto das espécies domesticadas quanto das populações de abelhas silvestres (Garibaldi et al., 2013). As abelhas Apis mellifera L. têm sido as mais utilizadas em todo o mundo para a polinização de plantas cultivadas, em razão de seu fácil manejo, tamanho de suas colônias, sua abundância em diferentes ecossistemas e seu perfil generalista na busca de recursos. Some-se a tais benefícios a importância que representam em termos de produção de mel e de outros produtos apícolas. Em 2013, o valor da produção de mel no Brasil foi de 316 milhões de reais (Produção da pecuária municipal, 2014). No entanto, no país, é ainda incipiente a polinização dirigida com uso de abelhas $A$. mellifera como prática que visa o aumento de produtividade e de qualidade de frutos. Apesar da grande diversidade de espécies encontradas no território nacional, o uso das espécies nativas, principalmente as abelhas sem ferrão, na polinização de plantas cultivadas e produção de mel, tem recebido ainda menos atenção (Moure et al., 2007; Jaffé et al., 2015).

Os processos de expansão das áreas de produção e intensificação da agricultura têm ameaçado a biodiversidade e os serviços ecossistêmicos, inclusive a polinização (Garibaldi et al., 2011). De fato, trabalhos recentes têm mostrado o declínio de polinizadores silvestres e domesticados, com reduções registradas no número de espécies de polinizadores e nos serviços de polinização em diferentes regiões do globo (Potts et al., 2010). Vários fatores estão associados ao declínio das populações silvestres de polinizadores, em que a perda e fragmentação dos habitats naturais têm sido apontadas como as principais causas (Potts et al., 2010).

Associadas aos declínios das populações de abelhas silvestres na última década, mortalidades sucessivas de colônias manejadas de A. mellifera têm sido registradas nos Estados Unidos - em média 30\% de perdas de colônias, em avaliações consecutivas efetuadas entre 2006 e 2010, conforme vanEngelsdorp et al. (2007, 2008, 2010, 2011) - e em alguns países da Europa (Laurent et al., 2015). Desde os primeiros registros no continente norte americano, já no inverno de 2006-2007, verificou-se que colônias que entravam em colapso apresentavam características bem definidas, embora sem causa conhecida. Por ser reconhecido somente após ocorrido e por meio de um conjunto de sintomas, o fenômeno passou a ser tratado como uma síndrome e recebeu a denominação de "colony collapse disorder" (CCD), conforme vanEngelsdorp et al. (2009), em Português, distúrbio do colapso das colônias. Os sintomas da CCD são: a rápida perda de abelhas operárias, evidenciada pelo enfraquecimento ou morte da colônia com excesso de crias, em comparação ao número de abelhas adultas; ausência de crias e abelhas adultas mortas dentro ou fora da colmeia; e ausência de invasão imediata da colmeia por pragas como, por exemplo, traças (vanEngelsdorp et al., 2009). Os principais fatores que têm sido associados à síndrome são estresses causados por patógenos, manejo inadequado das colônias, uso de agrotóxicos, má nutrição e a combinação entre estes fatores (vanEngelsdorp et al., 2009).

Nesta revisão, apresentamos um breve histórico sobre a síndrome da CCD na América do Norte e Europa, além de uma compilação de alguns dos estudos mais relevantes relacionados às possíveis causas da CCD (nutrição, patógenos, parasitas e efeitos dos agrotóxicos) e discutimos, ainda, como as mudanças climáticas em curso podem afetar essa síndrome. Com o objetivo de responder à pergunta: "Existem casos comprovados de CCD no Brasil?", focou-se nos estudos que estão sendo realizados no país, principalmente sobre agrotóxicos em uso na nossa agricultura e os patógenos e parasitas que afetam as colônias manejadas das abelhas melíferas. Ao final, com base nas experiências de outros países, foram discutidas as possíveis medidas de mitigação e os principais estudos necessários à abordagem

Pesq. agropec. bras., Brasília, v.51, n.5, p.422-442, maio 2016 DOI: $10.1590 / \mathrm{S} 0100-204 X 2016000500003$ 
sobre declínios, enfraquecimentos e outros colapsos, levando-se em conta a realidade brasileira.

\section{Histórico da síndrome "distúrbio do colapso das colônias" nos Estados Unidos e na Europa}

Ainda não se sabe o momento exato em que as primeiras perdas de colônias de $A$. mellifera atribuídas à CCD ocorreram nos EUA e em outras áreas do mundo. Em 2006-2007, antes da polinização das amendoeiras, em fevereiro de 2007, apicultores do Estado da Califórnia observaram a ocorrência de colmeias que, em apenas algumas semanas, passaram rapidamente a apresentar condições precárias. Eles relataram que as colônias pareciam boas, mas, inexplicavelmente, perdiam as abelhas adultas em apenas algumas semanas, as quais morriam ou ficavam demasiadamente fracas para polinizar os campos de amendoeiras. Em 2006, o United States Department of Agriculture (USDA) realizou um levantamento nas colônias, em boas e más condições, mas não conseguiu identificar um organismo causador (patógeno ou predador) que explicasse as perdas. Um levantamento conduzido em 2007 pelos inspetores do Apiary Inspectors of America (AIA) estimou que os apicultores americanos perderam $30 \%$ de suas colmeias de $A$. mellifera, no outono e inverno daquele ano, ou cerca de 750 mil colmeias. Daquela perda total, cerca de 13\% (325 mil colônias) foi atribuída à $\mathrm{CCD}$, os outros $17 \%$ poderiam incluir algumas colônias com CCD, uma vez que é difícil separar todas as perdas em categorias distintas. Desde 2007, os levantamentos e registros têm sido conduzidos anualmente (vanEngelsdorp et al., 2007, 2008, 2010, 2011). Nos últimos anos, nos EUA, os levantamentos têm registrado perdas durante todo o ano e, em 2014, a perda total média ficou em torno de $43 \%$ de colônias de $A$. mellifera (Lee et al., 2015).

Esses inventários têm um valor inestimável na busca por tendências e têm direcionado as pesquisas para os problemas mais urgentes que os apicultores relatam como sendo as causas da morte de suas colônias. Uma tendência interessante é que o número de apicultores americanos que relataram sintomas de CCD em suas colmeias diminuiu nos últimos anos, mas as perdas médias anuais permaneceram quase tão altas quanto no pico dos relatos sobre a CCD, entre 2006 e 2008 (cerca de $30 \%$ de perda durante o inverno).
No início de 2007, foi realizada nos EUA uma reunião com a participação de cientistas de órgãos federais, universidades, representantes da indústria apícola e dos produtores, com o objetivo de identificar a causa ou causas da rápida mortalidade das colônias. Um conjunto de sintomas foi identificado e resultou na denominação dessa síndrome como "colony colapse disorder" (CCD). A partir daí foi criado um comitê de investigação e um de gestão da $\mathrm{CCD}$, este último encarregado de elaborar um plano de ação e relatar anualmente os progressos atingidos (Colony Collapse Disorder, 2015). O Comitê Gestor da CCD inclui governo federal e estaduais, universidades públicas e pesquisadores de instituições privadas, liderados pelo Agricultural Research Service (ARS) do Usda e pelo National Institute of Food and Agriculture (Nifa).

Inúmeras causas da CCD têm sido propostas e examinadas. No entanto, agora está claro que nenhum fator sozinho deve ser responsável pela síndrome. Níveis elevados de patógenos continuam a ser identificados nas abelhas afetadas pela CCD (Cox-Foster et al., 2007), sem que um patógeno específico possa ser associado definitivamente à síndrome (Cornman et al., 2012). Além disso, avaliações quanto ao ácaro Varroa destructor, um parasita já conhecido, e quanto ao microsporídio Nosema ceranae que, inicialmente, eram suspeitos de desempenhar papel importante na $\mathrm{CCD}$, não foram capazes de evidenciar a responsabilidade destes pela síndrome. Estudos têm mostrado que as abelhas estão expostas a uma ampla gama de agrotóxicos (Mullin et al., 2010; Pettis et al., 2013) e que alguns deles têm efeitos sinergísticos com outros agrotóxicos ou com parasitas ou patógenos que acometem as abelhas (Pettis et al., 2013). Em geral, esses estudos sustentam a hipótese de que a CCD é uma síndrome relacionada à sobrecarga de estresse, causada por diferentes fatores que atuam em combinação ou sinergisticamente (Cornman et al., 2012). No entanto, mais dados são necessários para confirmar totalmente essa hipótese e, assim, estudos com essa abordagem continuam a ser conduzidos.

Embora as causas da CCD não tenham sido totalmente esclarecidas, as pesquisas estão sendo conduzidas por equipes multidisciplinares, de forma coordenada e com foco em resolver o problema (Pettis \& Delaplane, 2010). Neste sentido, vários projetos estão sendo financiados pelo Nifa e pelo Agricultural Research Service (ARS). Como resultado, com contribuições 
adicionais de uma série de outras fontes, como National Honey Board, Almond Board of California, Burt's Bees, Häagen-Daz, North American Pollinator Protection Campaign, Project Apis, Foundation for the Preservation of Honey Bees e outras, tem surgido uma variedade de estudos e agregação de novas competências que trabalham em questões relacionadas à sanidade apícola.

O laboratório do ARS, em Beltsville, identificou que uma nova espécie de Nosema - N. ceranae está presente nos EUA desde pelo menos 1995. Este parasita do trato digestivo continua a impactar a saúde das abelhas, mas não parece ser a única causa da CCD. Viroses relacionadas à saúde das abelhas continuam a ser investigadas, especialmente em conjunto com a infestação do ácaro $V$. destructor .

O impacto do transporte de colônias de abelhas (apicultura migratória) e sua relação com a CCD também têm sido investigados pelo USDA-ARS e universidades. Grande parte do trabalho sobre o estresse causado pela migração das colônias está sendo realizado pelo Projeto Areawide on Honey Bee Health do ARS (Pettis \& Delaplane, 2010). O objetivo destas pesquisas sobre o estresse das migrações é desenvolver um conjunto de práticas de manejo mais adequadas para os apicultores migratórios. Dados preliminares apontaram perda de 30\% dos imaturos nas colônias transportadas, em comparação com aquelas que permaneceram fixas. Sondas de temperatura colocadas em colmeias experimentais mostraram certa incapacidade das abelhas de manter a temperatura estável na colônia (termorregulação), o que foi correlacionado à perda de crias. Ahn et al. (2012) observaram que as glândulas hipofaringeanas das abelhas nutridoras, de colônias transportadas por longas distâncias, têm menor volume em comparação àquelas de abelhas de colônias fixas. Isso provavelmente afeta a capacidade de alimentar a prole em abelhas nutridoras, o que pode levar ao enfraquecimento da colônia.

Com relação à nutrição, o Usda desenvolveu, em parceria com a iniciativa privada, o MegaBee ou o Tucson Bee Diet, uma dieta suplementar de proteínas comparável ao pólen coletado naturalmente, quanto à atratividade para as abelhas, às taxas de consumo e ao estímulo do crescimento da colônia. A dieta MegaBee e outras dietas comerciais são um componente importante para mitigar o impacto da má nutrição sobre a saúde da colônia e poderá auxiliar, assim, a prevenção contra a CCD (DeGrandi-Hoffman \& Chen, 2015).

De acordo com o Plano de Ação da CCD, amostras de abelhas também estão sendo analisadas extensivamente quanto aos agrotóxicos pela Pennsylvania State University, pelo ARS-Beltsville e pelo Departamento de Agricultura da Pensilvânia, em cooperação com os laboratórios Agricultural Marketing Service (AMS) do USDA. Por meio do genoma da abelha melífera recentemente sequenciado, os pesquisadores descobriram que as abelhas podem ter um menor número de enzimas desintoxicantes, o que as torna especialmente suscetíveis aos agrotóxicos. Assim, embora não se tenha confirmado nenhum padrão de exposição a agrotóxicos com as mortes, as abelhas de colônias associadas à CCD continuarão a ser analisadas quanto à exposição a agrotóxicos e doenças. Vários estudos têm mostrado que uma ampla gama de agrotóxicos pode ser encontrada nas colônias (Mullin et al., 2010) e que estes compostos podem interagir com agentes patogênicos (Pettis et al. 2013). Efeitos de inseticidas sobre as rainhas foram documentados, mas o efeito em toda a colônia muitas vezes não é observado de forma significativa (Sandrock et al., 2014; Dively et al., 2015). Outros estudos de campo foram realizados, mas os resultados ainda são controversos (Pilling et al., 2013; Cutler et al., 2014; Rundlöf et al., 2015).

$\mathrm{Na}$ Europa, a perda de colônias não é um fenômeno novo, e a CCD por si só não tem sido amplamente registrada. As avaliações oficiais de perdas de colônias são mais recentes do que nos EUA e não estão disponíveis com a mesma periodicidade, como ocorre no continente americano, pois envolve adesão de países da UE, bem como o engajamento de órgãos para a padronização de metodologia em tais avaliações (Laurent et al., 2015). Após a introdução do ácaro Varroa, na década de 1970, as perdas de colônias passaram a ser elevadas na Europa, apesar das tentativas de controle feitas pelos apicultores (De Jong, 1982; Genersch et al., 2010). Entre 2006 e 2008, a Europa sofreu perdas de colônias, embora para tais perdas não se tenha constatado sintomas semelhantes àqueles associados à CCD nos EUA. Na Europa, os ácaros Varroa ou a exposição a agrotóxicos têm sido apontados como os causadores das perdas de colônias (Genersch et al., 2010). No início da década de 2000, os apicultores franceses culparam os inseticidas 
neonicotinoides, usados na cultura do girassol (Helianthus annuus L.), pela morte de colônias de A. mellifera. Alguns estudos investigaram esta associação, mas não conseguiram mostrar exposição suficiente aos agrotóxicos que pudesse causar tais perdas de colônias (Chauzat et al., 2010). Os efeitos do Varroa são muitas vezes mais claros, e monitoramentos conduzidos na Alemanha têm mostrado que, em alguns anos, esse ácaro pode ser apontado como um fator significativo de perda de colônias (Genersch et al., 2010). No entanto, o uso de neonicotinoides em canola (Brassica napus) e perdas de colônias ocorridas no Reino Unido foram investigados no período de 2000 a 2010 e foi encontrada relação significativa entre o uso de imidaclopride (inseticida do grupo dos neonicotinoides) e perdas de colônias de $A$. mellifera (Budge et al., 2015). Com base em vários outros estudos, a União Europeia, em 2014, suspendeu o uso de vários inseticidas desse grupo para reavaliação, com decisão definitiva marcada para o fim de 2015. Assim, na Europa e ao redor do mundo, continua o debate sobre o papel da exposição aos agrotóxicos nas perdas de colônias de A. mellifera (Godfray et al., 2014).

Um grupo de trabalho que coordenou a pesquisa sobre o Varroa por muitos anos na Europa foi transformado em uma rede de pesquisa mais ampla, que tem investigado as perdas de colônias associadas a todos os fatores. Esse grupo foi denominado Colony Loss Network ou Coloss (Coloss, 2015a). A rede Coloss não visa financiar as investigações, mas tem como objetivo coordenar as atividades de pesquisa em toda a Europa e tem trabalhado para ser uma rede de pesquisa mundial, que inclui pesquisadores de outros continentes. A Coloss tem todos os três grupos envolvidos com a problemática: cientistas, apicultores e indústria, visando complementar as abordagens de investigação e criar novas alianças e sinergias entre os membros da rede. Esta rede tem publicado artigos-chave, relacionados às perdas de colônias (Coloss, 2015b) e publicou o Bee book - standard methods for Apis mellifera research, que propôs metodologias padronizadas a serem utilizadas nas pesquisas com as abelhas melíferas.

O fenômeno CCD foi e continua sendo amplamente estudado, mas ainda existem muitas perguntas sem respostas, considerando-se toda a complexidade que naturalmente norteia uma síndrome, a exemplo de muitas síndromes que afetam outras espécies, inclusive a humana, após décadas de estudos. Recentemente, os estados-membros da União Europeia, em relatório de 2012-2014 (Laurent et al., 2015), têm disponibilizado vultosos recursos para pesquisas, com o objetivo de conhecer os fatores envolvidos nessa síndrome.

\section{Enfraquecimento e perda de colônias no Brasil}

No continente latino-americano, apesar da relevância econômica que a atividade apícola representa, o status da sanidade apícola no que tange à problemática da CCD não está bem documentado, com ausência de relatos sobre perdas massivas devidas ao fenômeno (Vandame \& Palacio, 2010). Até o início dos anos 2000, não havia registros na literatura sobre a perda de colônias de $A$. mellifera no Brasil, com exceção de perdas ocorridas em virtude de indisponibilidade de recursos naturais (secas prolongadas), manejo inadequado (em especial relacionados à manutenção de rainhas improdutivas, entre outros fatores) ou em razão do pólen tóxico de barbatimão (Stryphnodendron spp.) (Carvalho \& Message, 2004; Castagnino et al., 2011).

A partir de 2007, é possível constatar o uso de termos como "declínio" e "colapsos" de colônias no país, em congressos e na mídia popular (jornais e revistas impressas ou portais digitais), em que se procura estabelecer semelhanças com o fenômeno da CCD identificado nos Estados Unidos. Em 2010, foi levantada a possibilidade de ocorrências de CCD em abelhas africanizadas na região sudeste do país (no município de Altinópolis, SP), com características semelhantes às descritas pelos americanos, todavia, sem causas estabelecidas. Igualmente, sem definição de causas, constatações de crias amareladas, amarronzadas e com aparência anômala (abdômen retraído e ressecado) foram relatadas. Embora os apiários estudados estivessem em área de plantio de cana-de-açúcar e eucalipto (com considerável uso de neonicotinoides e fipronil) e, ainda, tenha sido constatada a presença de $V$. destructor e de diversos patógenos, entre os quais vírus e o fungo $N$. ceranae (Teixeira et al., 2008a, 2012), não foi possível concluir qual seria a causa ou causas de tais colapsos. Fica patente a necessidade de estudos que ampliem e aprofundem tais conhecimentos, inclusive avaliações de possíveis efeitos sinergísticos entre os compostos e os patógenos presentes, em todas as fases de desenvolvimento das abelhas. 
Em 2007, as primeiras amostras de abelhas A. mellifera africanizadas, oriundas de apiários brasileiros da região Sudeste, cujas colônias apresentavam enfraquecimento e queda de produção repentinas, foram enviadas ao Bee Research Laboratory, USDA, Beltsville, EUA, como parte de pesquisa desenvolvida pela Agência Paulista de Tecnologia dos Agronegócios, da Secretaria de Agricultura e Abastecimento de São Paulo (Apta, SAA-SP), em colaboração com a Universidade Federal de Viçosa, para identificação de patógenos com a aplicação das mesmas ferramentas moleculares utilizadas nas amostras diagnosticadas com CCD naquele país. Naquela ocasião, os dados da presença de patógenos e das características observadas nessas colônias não indicaram que essas mortalidades registradas nos apiários brasileiros estivessem associadas à CCD.

Relatos de mortes em massa de $A$. mellifera também têm sido reportados por apicultores à Apta e ao Centro de Estudos de Insetos Sociais da Universidade Estadual Júlio de Mesquita Filho, em Rio Claro, SP, e a membros do Comitê Científico Consultivo de Sanidade Apícola do Mapa. Todavia, para que se tornem dados oficiais, há a necessidade de registro por parte do órgão de defesa agropecuária da unidade federativa envolvida. Nosúltimos 10 anos, foram registradas perdas de dezenas de milhares de colmeias de abelhas africanizadas no Estado de São Paulo. Em algumas visitas ao campo, pela equipe do Laboratório de Ecotoxicologia e Conservação de Abelhas, da Universidade Federal de São Carlos, observou-se um número elevado de operárias mortas no entorno das colmeias, mas não se observou nenhuma das características associadas à $\mathrm{CCD}$. As causas dessas perdas não foram efetivamente investigadas. A hipótese levantada para explicar essas mortalidades em massa é a aplicação de agrotóxicos nas áreas próximas dos apiários, além do uso incorreto dos diferentes tipos de aplicação existentes.

No entanto, não há dados sobre mortalidade de abelhas melíferas manejadas e nativas efetivamente registrados, relacionados à presença de patógenos, exposição aos agrotóxicos ou a combinação desses fatores, em razão da inexistência de um sistema de monitoramento das colônias nos apiários, meliponários e também nos ambientes naturais. No Brasil, não se tem cadastro amplo e efetivo de apicultores e meliponicultores, salvo iniciativas individualizadas de pouquíssimos estados, geralmente incompletas. Ainda, praticamente inexistem registros de deslocamentos de colmeias, por parte do produtor e órgãos oficiais envolvidos. A ausência de programas governamentais devidamente regulamentados, que visem avaliar a situação real da sanidade apícola em território nacional, constitui-se também em fato que contribui sobremaneira para tal situação. Ao se considerar o que é preconizado pela Organização Mundial da Saúde Animal (OIE, World Organisation for Animal Health), quanto ao controle que deveria ser executado por organismos oficiais, no que diz respeito às doenças que acometem as abelhas, constante em seu Código Terrestre de Saúde Animal (World Organisation for Animal Health, 2015), os dois primeiros e principais itens requeridos não são efetuados apropriadamente no Brasil. O primeiro está relacionado ao registro de apiários pelas autoridades competentes em todo o país. Esse registro é importante para que levantamento ou controle de doenças possam ser efetuados. Órgãos executores de Defesa Agropecuária de pouquíssimos estados iniciaram tais cadastros, bem como alguns organismos de representação de classe, que se encontram, todavia, ainda incompletos e falhos. Porém, não há uniformização de tais cadastros, o que inviabiliza a comunicação entre os poucos e diferentes sistemas elaborados com vistas a serem usados como ferramentas em ações padronizadas e coordenadas. O segundo item abrange a organização, por parte de órgãos oficiais para levantamentos sistemáticos, o que inclui coletas contínuas, acompanhadas de avaliações apropriadas que permitam pronta disseminação da informação obtida. O não atendimento a estes dois itens inviabiliza a geração de informações confiáveis, para emissão de documentos oficiais que atestem a saúde das colônias de uma determinada região e que compõem os requisitos propostos pelo organismo regulamentador internacional OIE, do qual o país é signatário. Assim, sem o conhecimento do efetivo de produtores e colônias presentes no Brasil, não há chance de se mensurar a magnitude das perdas, sejam atribuídas à $\mathrm{CCD}$ ou a outros tipos de colapso. A implementação de redes de laboratórios que deem suporte aos levantamentos epidemiológicos é essencial. Atualmente, existe no Brasil apenas um laboratório especializado (Apta, SAA-SP), o qual não tem condições de atender à demanda nacional. Assim, pelo menos um laboratório oficial por região do país seria necessário, de forma a atender problemas sanitários específicos. 


\section{Possíveis causas da CCD}

\section{Estado nutricional e manejo das colônias}

A deficiência nutricional da colônia afeta as reservas de alimento, os cuidados com as crias, aumenta o canibalismo e prejudica o estado nutricional das gerações subsequentes de operárias (Brodschneider $\&$ Crailsheim, 2010). Problemas nutricionais afetam o sistema imunológico das abelhas e das colônias e estão associados às causas da CCD (DeGrandi-Hoffman \& Chen, 2015). O sistema imunológico individual é importante para a prevenção de doenças causadas por microrganismos. Nas abelhas, a resistência individual inclui as barreiras mecânicas (cutícula, epiderme), barreira fisiológica (com mudanças de $\mathrm{pH}$ e outras mudanças químicas do intestino das abelhas) e o sistema imunológico, entre outros (Evans \& Spivak, 2010). A resposta imune dos insetos é afetada pela baixa disponibilidade de aminoácidos essenciais, imprescindíveis para a síntese de peptídeos do sistema imunológico, e pela carência de carboidratos que reduz a disponibilidade de energia metabólica necessária aos processos associados ao sistema imunológico (Cotter et al., 2011).

Se, por um lado, a desnutrição afeta a imunidade e facilita a infestação por parasitas, por outro, o parasitismo afeta o estado nutricional do organismo. Assim, a relação entre nutrição e resposta imunológica aos parasitas não é tão simples, além disso, há interação entre estes fatores. A infestação de operárias nutrizes de $A$. mellifera pelo ácaro Varroa interfere na quantidade de alimento fornecido às larvas e no teor de aminoácidos essenciais na hemolinfa das operárias (Aronstein et al., 2012). O parasitismo por Varroa causa a disseminação de vírus e redução do metabolismo de proteínas essenciais ao sistema imunológico das abelhas (Alaux et al., 2011; DeGrandi-Hoffman \& Chen, 2015).

As maiores fontes de alimento das abelhas são o néctar, que será transformado em mel, e o pólen que é fermentado por microrganismos presentes no trato digestório das abelhas. Esses alimentos possuem uma variação nutritiva muito grande, que ocorre de acordo com a espécie botânica de onde são obtidos, e fornecem todos os nutrientes essenciais. A deficiência de algum destes nutrientes pode prejudicar o desenvolvimento, manutenção e reprodução das colônias, reduzir a vida das abelhas, provocar estresse e facilitar o aparecimento de doenças (Pereira et al., 2011). Pesquisas para determinar as exigências nutricionais das abelhas não são fáceis de serem realizadas, pois cada casta tem sua necessidade. As exigências nutricionais são diferentes entre crias e adultos e são reguladas de acordo com a idade, função dos adultos na colônia, época do ano e taxa metabólica.

Atualmente, recomenda-se a suplementação das colônias sempre que necessário, mesmo em períodos produtivos. O nível ótimo de desenvolvimento das colônias ocorre quando se fornecem 20 a $23 \%$ de proteína bruta e todos os aminoácidos considerados essenciais (De Groot, 1953). Considera-se também importante que o alimento, natural ou formulado, contenha os aminoácidos não essenciais - glicina, serina e prolina -, para estimular o crescimento em A. melifera, pois a deficiência de qualquer um destes aminoácidos pode prejudicar a síntese das proteínas que os contêm (Dadd, 1973; Brodschneider \& Crailsheim, 2010). Os carboidratos são importantes no fornecimento da energia que será usada na síntese da matéria orgânica, contração muscular, condução de impulsos nervosos, produção de aminoácidos, produção de cera, entre outros. Contudo, nem todo açúcar pode ser metabolizado. Glicose, frutose, sacarose, maltose, trealose e melezitose podem ser utilizadas pelas abelhas adultas, e os quatros primeiros são usados com maior eficiência (Brodschneider \& Crailsheim, 2010). Embora importantes, as exigências nutricionais de vitaminas e sais minerais são pequenas e por vezes é difícil determinar a quantidade necessária ou a influência desses no metabolismo dos insetos. $\mathrm{O}$ fornecimento de xarope enriquecido com vitamina $\mathrm{C}$ aumenta a síntese proteica, o peso corporal das abelhas adultas e a quantidade de cria nas colônias (Andi \& Ahmadi, 2014), o que deve influenciar o sistema imunológico individual e coletivo. $\mathrm{O}$ teor de zinco do pólen de uma região pode variar de 5,1 a $340,0 \mathrm{mg} \mathrm{kg}^{-1}$, contudo um teor menor que $30,0 \mathrm{mg} \mathrm{kg}^{-1}$ é insuficiente para manter as colônias saudáveis. Assim, sugerese o fornecimento de solução de sacarose a $50 \%$, enriquecida com $30 \mathrm{mg} \mathrm{kg}^{-1}$ de zinco, para aumentar a atividade antioxidante e a longevidade das operárias, conforme Zhang et al. (2015). Estes autores também recomendam o enriquecimento do xarope com 60 a $75 \mathrm{mg} \mathrm{kg}^{-1}$ de zinco para melhorar a qualidade das larvas produzidas. 
A abundância e diversidade de pólen influencia a saúde dos polinizadores. Dietas poliflorais deixam o sistema imunológico mais eficiente do que dietas monoflorais (Alaux et al., 2011). Nas operárias de colônias que possuem dieta diversificada, observase aumento da concentração de hemócitos e do peso do corpo gorduroso (indicadores imunológicos ou de capacidade imunológica individual) e alta atividade da glicose-oxidase (indicador imunológico social) (Alaux et al., 2011). Para as abelhas, o valor nutritivo do pólen depende, além da diversidade, da disponibilidade de nutrientes, em especial dos aminoácidos essenciais, de sua digestibilidade e da presença de outros nutrientes, como lipídeos e carboidratos (Frias et al., 2015).

A composição química do pólen pode variar de acordo com a espécie vegetal, condições ambientais, idade e estado nutricional da planta, região, estações do ano e mesmo de acordo com o ano (Szczesna et al., 2002). Assim, é essencial o conhecimento da composição nutricional do pólen apícola produzido, como estratégia de alimentação artificial das colônias nos períodos de escassez de alimento. A qualidade da dieta de pólen influencia diretamente a fisiologia, saúde e sobrevivência da abelha e pode causar efeitos negativos no comportamento de forrageamento e capacidade de alimentação da cria por abelhas nutridoras (Frias et al., 2015). Uma deficiência da quantidade e qualidade do pólen e néctar leva à redução do número de abelhas nas colônias e da quantidade de colônias em uma região. As pesquisas mostram que as perdas de colônias podem ser reduzidas, se o estresse decorrente de dietas desbalanceadas for aliviado com o uso de práticas que valorizem os recursos florais nos agroecossistemas (Decourtye et al., 2001).

O desmatamento e as grandes áreas de monocultura têm afetado a composição florística da paisagem e contribuído para o declínio dos polinizadores (Donkersley et al.,2014). Adieta das abelhas A. mellifera inclui plantas dos mais diversos grupos, uma vez que são generalistas na exploração de recursos florais. Em áreas com vegetação diversificada, ao terem acesso ao pólen de diversas fontes, as abelhas garantem uma alimentação balanceada, compensando a deficiência de nutrientes de algumas espécies de plantas. No entanto, colônias instaladas em regiões com extensas áreas de monocultura sofrem com deficiência de nutrientes essenciais, o que afeta a imunidade (Brodschneider \& Crailsheim, 2010). Essa condição tem sido observada frequentemente em colônias destinadas aos serviços de polinização, que são instaladas geralmente em locais de monocultura e ficam sujeitas a uma dieta menos variada e, consequentemente, mais pobre (Brodschneider \& Crailsheim, 2010).

Além disso, também pode ocorrer estresse em consequência das condições e da frequência do transporte das colmeias. Nos Estados Unidos, por exemplo, nas grandes empresas que prestam serviços de polinização, as colmeias são transportadas em caminhões por longas distâncias e podem mudar de lugar de duas a cinco vezes por safra, conforme Ahn et al. (2012), que observaram que, além dos aspectos nutricionais, o confinamento e as flutuações de temperatura nas colônias constituem fatores estressantes adicionais que podem aumentar a suscetibilidade a doenças, além de expor as colônias a outros parasitas e patógenos. No entanto, a migração de colônias em serviços de polinização nem sempre é considerada um fator importante para o aumento das perdas anuais, desde que o estresse causado pela migração seja minimizado ou compensado por práticas adequadas de manejo (vanEngelsdorp et al., 2010).

Em muitos países, e particularmente no Brasil, as perdas anuais de colônias podem ser atribuídas ao manejo inadequado. Fatores como exposição a fontes de água limitadas ou contaminadas, falta de sombreamento em regiões de climas quentes, não fornecimento de alimentação suplementar, uso de quadros velhos, ataque de inimigos naturais e não substituição de rainhas têm sido apontados como causas de perdas de colônias, além do pólen do barbatimão (Haddad, 2011; Message et al., 2012; Vidal, 2013; Souza et al., 2014; Holanda-Neto et al., 2015).

\section{Patógenos, parasitas e predadores}

Um histórico circunstanciado da sanidade apícola no Brasil foi recentemente compilado por Message et al. (2012) e trouxe informações sobre os primeiros registros de diversos patógenos, parasitas e predadores relacionados às abelhas melíferas em território nacional: a bactéria Melissococcus pluton, atualmente Melissococcus plutonius; o fungo Aschosphaera apis; os parasitas Acarapis woodi e Varroa jacobsoni (atualmente Varroa destructor); os protozoários Malpighamoeba mellificae e Nosema apis (atualmente classificado como fungo); os nematoides Agamomermis sp. e Gordius sp.; as moscas Melaloncha ronnai, Sarcophaga surrubea e Braula coeca; as traças 
Achroia grisella e Galleria mellonela; o percevejo Apiomerus lanipes; a formiga Myrmeleon januarius. Estes autores também apresentaram a identificação de alguns vírus por meio da técnica de dupla imunodifusão (Filamentous virus, Acute paralysis virus (ABPV), Black queen cell virus (BQCV) e Cloudy wing virus (CWV)). Alguns destes patógenos e parasitas estão sendo associados à $\mathrm{CCD}$ nos Estados Unidos e na Europa.

Pesquisas recentemente desenvolvidas no Brasil estão centradas em uma das vertentes apontadas entre as causas de colapso: a possibilidade de envolvimento de patógenos e parasitas (Teixeira et al., 2008a, 2008b, 2012, 2013; Santos et al., 2014; Schwarz et al., 2014); e a crescente vulnerabilidade das abelhas, em virtude da diminuição de mecanismos de defesa em casos de coinfecção (Cox-Foster et al., 2007; vanEngelsdorp et al., 2009). Entretanto, o conhecimento insuficiente sobre a localização das unidades produtivas (apiários) compromete o acesso ao conhecimento amplo sobre patógenos existentes no país. Infelizmente, no Brasil, não há monitoramento neste sentido, pois este é inviabilizado pelas precárias informações disponíveis quanto à localização de colônias em produção e de apicultores, associado às dimensões continentais do País. Outros pontos que dificultam as avaliações epidemiológicas são: a falta de informações sobre os manejos adotados nos apiários; a diversidade de flora e de culturas, no raio de ação das abelhas; e as práticas agrícolas ali adotadas, principalmente quanto ao uso de agrotóxicos.

Estudos foram conduzidos em localidades específicas da região Sudeste do Brasil, em populações de A. mellifera africanizadas, que apresentaram problemas sanitários identificados como enfraquecimento repentino e perda de colônias, em especial entre os meses de março e julho (outono e inverno) (Teixeira et al., 2008a, 2012). Colônias usadas em serviços de polinização, especialmente de macieira, em Santa Catarina, também foram avaliadas quanto às perdas consideráveis registradas pela Federação daquele estado (Gonçalves, 2012). Vinte e quatro notificações de ocorrência de problemas sanitários foram atendidas em apiários de Santa Catarina e, no ano de 2012, realizouse o monitoramento em 18 apiários, no total de mais de 500 amostras de abelhas analisadas pela Apta, advindas de áreas que apresentaram problemas sanitários em
2011, devidamente notificados ao órgão oficial de defesa agropecuária do Estado (Mitidiero, 2013).

Os escassos levantamentos epidemiológicos já realizados no Brasil são pontuais e efetuados especialmente nas regiões Sul e Sudeste. Pouco se conhece sobre a situação sanitária dos apiários do Centro-Oeste, Nortee Nordeste doBrasil. Também, nada se conhece sobre a situação sanitária dos meliponários brasileiros, das colônias de abelhas nativas do Brasil (Message et al., 2012) ou de colônias de A. mellifera que se encontram na natureza. Em razão da diversidade de microrganismos associados às abelhas, nessas análises foi fundamental a aplicação de protocolos previamente estabelecidos por meio de colaboração da Apta com o Bee Research Laboratory-USDA, em Beltsville. Essas técnicas estão sendo utilizadas especialmente para testar as semelhanças com possíveis agentes envolvidos com a CCD (Cox-Foster et al., 2007). Assim, as primeiras identificações genético-moleculares de patógenos que infectam A. mellifera africanizadas no Brasil foram obtidas, e nenhum patógeno em particular pareceu ser predominante nas colônias afetadas pelo mencionado declínio, conforme Teixeira et al. (2008a), que relatam ainda que três vírus foram identificados Acute bee paralysis virus (ABPV), Black queen cell virus (BQCV) e Deformed wing virus (DWV) - e que, dos 1.920 indivíduos analisados, 43 apresentaram coinfecção, tendo sido 15 com ABPV e DWV, 19 com BQCV e DWV e 21 com ABPV e BQCV; entre esses indivíduos, apenas seis apresentaram coinfecção com os três vírus. Estes autores também constataram que aproximadamente $26 \%$ das amostras analisadas - que incluíam colônias onde foram relatadas perdas, enfraquecimentos repentinos e colônias sadias encontravam-se infectadas pelo vírus Israeli acute paralysis virus (IAPV), patógeno identificado como um dos responsáveis pela CCD nos Estados Unidos (Cox-Foster et al., 2007). Essa foi a primeira evidência do vírus IAPV na América do Sul e mostrou que a presença do vírus nas amostras brasileiras não estava relacionada ao declínio da população de abelhas adultas da localidade estudada, o que foi posteriormente confirmado por Teixeira et al. (2012).

Recentemente, Chen et al. (2014), por meio de complexo estudo de características biológicas e moleculares envolvidas na infecção causada pelo vírus IAPV em $A$. mellifera, mostraram que este é capaz de infectar todas as fases de desenvolvimento desta 
espécie de abelha (ovo, larva e abelhas adultas de todas as castas), embora sem sinais clínicos da infecção.

Os patógenos N. ceranae, M. plutonius, Leptomonas apis, e Spiroplasma apis foram também identificados nas amostras brasileiras, e as relações entre os patógenos foram estudadas por meio de técnicas moleculares. Foram identificadas correlações com outros patógenos presentes em amostras de A. mellifera, oriundas do Sudeste do Brasil (negativa para L. apis $x A B P V$ e positiva para ABPV $x$ BQCV e ABPV $x$ DWV), fato que pode indicar efeito sinergístico entre espécies de patógenos (Teixeira et al., 2008a). Ensaio multiplex RT-PCR ("reverse transcriptase-polymerase chain reaction") foi, posteriormente, desenvolvido e validado para as amostras brasileiras, quanto a alguns dos principais vírus identificados (BQCV, ABPV e DWV (Teixeira et al., 2008b). A ocorrência comum de muitos vírus em populações de $A$. mellifera, oriundas de colônias que aparentam características saudáveis mesmo quando diferentes vírus estão presentes, sugerem que infecções não aparentes podem permanecer presentes por muitas gerações, causando pouco ou nenhum dano, vindo a desencadear, em condições favoráveis, replicação rápida ou infectar de forma aguda a colônia, frequentemente com infecção fatal (Miranda et al., 2012). Esta problemática relacionada à presença de vírus em $A$. mellifera vem sendo discutida há décadas, em virtude da considerável dificuldade de avaliação e diagnóstico de infecções virais nessas abelhas em campo, considerando-se os sintomas não específicos e não aparentes, além da diversidade de 18 tipos virais que podem acometê-las (Bailey \& Ball, 1991).

Diante da possibilidade de rota de transmissão de vírus, em que o ectoparasita $V$. destructor teria importante papel como vetor (Sumpter \& Martin, 2004), alguns estudos têm avaliado a possibilidade da presença de vírus em $A$. mellifera associado à presença do ácaro, com evidência de distribuição sazonal que atinge seu ápice coincidentemente no pico de infestação de $V$. destructor em países europeus (Miranda et al., 2015).

No Brasil, as abelhas africanizadas apresentam algumas características que favorecem a resistência ao ácaro, inclusive elevada infertilidade do parasita nesse biótipo (Rosenkranz, 1999), o que pode explicar os baixos níveis de infestação observados no país (Strapazzon et al., 2009; Santos et al., 2014).
Aparentemente, há grande variação da taxa de infestação conforme a região do país, em consequência das variações climáticas, e conforme as linhagens.

O fungo unicelular $N$. ceranae também tem sido alvo de estudos nas populações de $A$. mellifera. Ambos os patógenos $-V$. destructor e $N$. ceranae - vêm sendo associados à presença de vírus em colônias de A. mellifera (Miranda et al., 2012) e têm sido indicados como possíveis responsáveis pela CCD no hemisfério norte, junto com o vírus IAPV (Cox-Foster et al., 2007) e o vírus Invertebrate iridescent virus (IIV) (Bromenshenk et al., 2010).

Análises realizadas em abelhas africanizadas, com os parasitas $V$. destructor e $N$. ceranae e o vírus IAPV, não confirmaram a hipótese de associação da presença deles, isolados ou em coinfecção, com colapsos no Brasil (Teixeira et al., 2008a, 2012; Santos et al., 2014). O vírus IIV ainda não foi pesquisado em abelhas oriundas do Brasil, e Tokarz et al. (2011), ao utilizar os mesmos dados metagenômicos dos estudos de Bromenshenk et al. (2010), com amostras de colônias com ou sem CCD, mostraram a ausência da associação do vírus IIV com o fenômeno CCD.

O possível envolvimento do microsporídio $N$. ceranae foi reportado em colapsos de colônias nos Estados Unidos e Europa (Cox-Foster et al., 2007; Paxton et al., 2010), no entanto, sabe-se que o patógeno está presente em todos os continentes, inclusive a América do Sul, onde colapsos ainda não estão bem documentados sistematicamente (Klee et al., 2007; Martín-Hernández et al., 2007). Embora o primeiro registro do patógeno no Brasil tenha sido feito somente em 2007 (Klee et al., 2007), recentemente foi confirmada a presença do microsporídio no país há pelo menos três décadas (Teixeira et al., 2013). A ampla prevalência da espécie $N$. ceranae em relação a $N$. apis foi também relatada, já que, de 637 amostras de abelhas oriundas de 10 estados brasileiros (São Paulo, Santa Catarina, Paraná, Rio de Janeiro, Maranhão, Ceará, Mato Grosso do Sul, Bahia, Minas Gerais e Goiás), 79\% estavam infectadas com Nosema, das quais $98,82 \% \operatorname{com} N$. ceranae, $0,39 \%$ com $N$. apis (registrado em Caçador, SC e Tamarana, PR), e 0,79\% das amostras estavam infectadas por ambas as espécies (Teixeira et al., 2013; Santos et al., 2014). Embora $N$. ceranae esteja amplamente presente no Brasil, não parece haver padrão quanto à intensidade da infecção deste microsporídio ao longo do ano, em território 
nacional (Teixeira et al., 2013), nem sinais clínicos ou relação direta com colapsos, o que parece indicar seu baixo impacto biológico sobre abelhas africanizadas.

Considerando-se antigos relatos sobre a presença de bactéria do gênero Spiroplasma em abelhas moribundas ou mortas coletadas fora de colmeias nos Estados Unidos (Clark, 1977), e a identificação dessa bactéria em abelhas africanizadas oriundas de apiários do Brasil, cujas colmeias apresentavam histórico de enfraquecimento (Teixeira et al., 2008a), duas espécies, $S$. apis e $S$. melliferum, foram estudadas em 139 amostras de abelhas melíferas coletadas em apiários brasileiros, entre 2011 e 2013 (Schwarz et al., 2014). Verificou-se que as diferenças observadas nas taxas de infecção e coinfecção das bactérias, nos dois países, pode ter sido consequência de maior disponibilidade de recursos florísticos ao longo do ano, na região tropical, já que esses recursos são importantes vias de transmissão e facilitadoras do ciclo das duas espécies de bactéria em um mesmo indivíduo (Schwarz et al., 2014). As amostras brasileiras foram coletadas nos estados de Santa Catarina, São Paulo, Bahia, Ceará, Goiás, Minas Gerais, Mato Grosso do Sul, Paraná, Rio de Janeiro, Rio Grande do Norte e Rio Grande do Sul, com predominância de amostragens nos dois primeiros. Os resultados obtidos comprovaram que as variações de prevalência da bactéria no Brasil e nos EUA são dependentes de variações geográficas, climáticas e temporais. Com as evidências de alterações de resposta imune, em abelhas infectadas por diferentes microrganismos, há possibilidade de a bactéria tornar o inseto mais suscetível a outros patógenos.

Além dos microrganismos, dois ácaros também foram identificados recentemente em alguns apiários brasileiros: larvas de Leptus sp. aderidas ao corpo de abelhas campeiras, em colônias localizadas em São José dos Campos, SP (Teixeira, 2008) e Tyrophagus putrescentiae, em diferentes estágios de desenvolvimento, que infestaram colônias de apiário do município de Rio Negrinho, SC (Teixeira et al., 2014). Com relação às larvas de Leptus sp., o relato por parte do produtor - de cerca de $20 \%$ de mortalidade de abelhas adultas em suas colônias -, não pôde ser conclusivamente relacionado à infestação do ácaro, visto que não foram observados ácaros aderidos às abelhas adultas mortas, coletadas na frente do alvado (Teixeira, 2008). Quanto à infestação de T. putrescentiae, embora a identificação tenha sido feita em amostras de apiário proveniente da região Sul, onde produtores relataram enfraquecimento e perdas de colônias, não se constataram abelhas mortas dentro ou no entorno das três colmeias infestadas com esse ácaro (Teixeira et al., 2014). Estudos mais detalhados, que visem avaliar a relação de tais ácaros com $A$. mellifera (se parasita ou comensal), são necessários. Também, em razão da presença de T. putrescentiae em pupas, abelhas adultas, células vazias e "pão de abelha" (pólen fermentado estocado nos favos), avaliações quanto a possíveis danos à saúde humana, em virtude da ingestão de tais ácaros, devem ser consideradas (Teixeira et al., 2014).

Avaliações de expressão gênica foram também conduzidas com as amostras brasileiras, com o objetivo de avaliar a expressão de genes relacionados a diferentes processos de defesa das abelhas $A$. mellifera (Evans, 2006), sem que houvesse, no entanto, diferenças entre as colônias, sejam as acometidas pelo enfraquecimento, sejam as classificadas como sadias (Teixeira et al., 2008a).

$\mathrm{O}$ projeto Honey Bee Genome Sequencing Consortium (Baylor College of Medicine Human Genome Sequencing Center, 2015), bem como outros esforços recentes, representam uma fonte de conhecimento de genes relacionados aos mecanismos de resistência das abelhas a certos patógenos (Whitfield et al., 2002; Evans, 2006). O entendimento da funcionalidade de tais genes pode gerar ferramentas que poderão ser usadas em programas de melhoramento assistido, que visam a seleção de indivíduos mais produtivos e mais resistentes às doenças. Considerandose a variabilidade genética existente nos apiários brasileiros, fruto dos cruzamentos aleatórios ocorridos naturalmente nos anos que sucederam a introdução da subespécie africana, sugere-se a exploração de tais recursos, focando-se na busca de linhagens resistentes a doenças e mantendo-se a ausência de uso de medicamentos em apiários brasileiros. No Brasil, as abelhas africanizadas refletem décadas de introgressão entre as subespécies europeias e a subespécie africana A. mellifera scutellata (Vandame et al., 2002). As características genético-comportamentais das abelhas africanas foram amplamente preservadas neste processo, e um dos fatores do sucesso adaptativo das abelhas africanizadas está associado ao elevado nível de resistência a patógenos e parasitas (Vandame et al., 2002; Schneider et al., 2004). 


\section{O uso de agrotóxicos na agricultura}

$\mathrm{Na}$ agricultura brasileira atual, baseada no alto uso de insumos, o controle de pragas e doenças está centrado principalmente no uso de diversas classes de agrotóxicos, como herbicidas, fungicidas e inseticidas entre outros. Até pouco tempo, a intoxicação das abelhas por agrotóxicos era relacionada exclusivamente à exposição letal (intoxicação aguda), que resulta em indivíduos mortos próximos às colônias. Atualmente, a preocupação aumenta com as possíveis consequências dos efeitos subletais às abelhas, aqueles que não levam à morte imediata, mas podem afetar o comportamento, o desenvolvimento e o sistema imunológico, alterando a capacidade de combater infecções e causando problemas crônicos provocados por exposição em longo prazo (Frazier et al., 2008; Whitehorn et al., 2012).

Vários estudos têm relacionado o crescente uso de agrotóxicos e seus efeitos subletais com o fenômeno CCD no hemisfério norte, principalmente os inseticidas do grupo dos neonicotinoides (Goulson, 2015). Os inseticidas desta classe já foram relacionados a alterações comportamentais e morfofisiológicas (Suchail et al., 2001; Decourtye et al., 2004) que afetam a capacidade de forrageamento (Yang et al., 2008; Schneider et al., 2012), aprendizagem (Decourtye et al., 2004) e vigor da colônia (Whitehorn et al., 2012).

Os efeitos dos neonicotinoides sobre as abelhas em situações reais de campo têm sido questionados, uma vez que a maioria dos estudos foi realizada em laboratório, e os dados de campo levantados até o momento são contraditórios. Em estudos de campo, realizados com tiametoxam por Pilling et al. (2013) e com clotianidina por Cutler et al. (2014), ambos no tratamento de sementes e com as doses recomendadas, nenhum efeito adverso foi observado sobre as abelhas campeiras. No entanto, Dively et al. (2015) encontraram alterações significativas na taxa de sobrevivência das abelhas expostas às doses de $20 \mathrm{e} 100 \mu \mathrm{g} \mathrm{kg}^{-1}$ de imidacloprido, em comparação ao grupo-controle, durante três anos. Porém, a dose de $5 \mu \mathrm{g} \mathrm{kg}^{-1}-$ dose residual encontrada nas matrizes vegetais, como pólen e néctar em girassol (Schmuck et al., 2001), e em coletas em diferentes culturas (Bonmatin et al., 2003) -, não causou alterações de comportamento de forrageamento e da taxa de sobrevivência. Os autores destacam que, mesmo não sendo os valores residuais mais comuns encontrados, as doses de 20 e $100 \mu \mathrm{g} \mathrm{kg}^{-1}$ podem ser encontradas em certas plantas (Dively \& Kamel, 2012). No entanto, Rundlöf et al. (2015) avaliaram, em campo, doses recomendadas da mistura de clotianidina (neonicotinoide) e beta-ciflutrina (piretroide), para o tratamento de sementes de canola, e encontraram efeitos negativos na comunidade de abelhas, como redução da abundância de abelhas silvestres e de nidificação da espécie solitária Osmia bicornis L. e diminuição da taxa de reprodução e do crescimento em colônias de mamangava (Bombus terrestris L.). Entretanto, colônias de A. mellifera não foram afetadas por essa mistura de inseticidas. Assim, estes autores propuseram que os dados obtidos sobre A. mellifera não sejam extrapolados para as outras espécies de abelhas e que outros estudos sejam feitos para entender o impacto real dos inseticidas sobre esse grupo de organismos.

Verifica-se que os resultados obtidos até o momento são controversos, e muitos estudos ainda são necessários, principalmente em relação às diferenças entre as diversas culturas sobre as quais os produtos são aplicados, as formas de aplicação, as rotas de exposição e a biologia das abelhas existentes nos agroecossistemas onde esses produtos são usados.

Além das consequências que provocam, os agrotóxicos podem interagir com diferentes patógenos, aumentando a suscetibilidade das abelhas a estes e potencializando seus efeitos. Doublet et al. (2015) mostraram que o neonicotinoide tiaclopride aumenta os efeitos deletérios de dois patógenos comuns à A. mellifera: o microsporídio $N$. ceranae e o vírus BQCV. Além disso, não só os inseticidas causam efeitos negativos às abelhas, como também diferentes grupos de ingredientes ativos usados na agricultura, encontrados em amostras de néctar e pólen, podem causar algum efeito deletério (Pettis et al., 2013).

Em bioensaios de laboratório, doses recomendadas do herbicida glifosato, usado no controle de certas plantas invasoras, afetaram o comportamento das abelhas quanto à sensibilidade à sacarose (Herbert et al., 2014), a habilidade de navegação (Balbuena et al., 2015) e o estabelecimento de sistemas complexos de associação (Herbert et al., 2014). Isto pode impactar a capacidade de forrageamento, coleta de alimento e retorno para a colônia. Pettis et al. (2013) observaram que amostras de pólen, coletadas por abelhas que retornaram à colônia após forragear em diferentes culturas, continham até 35 diferentes ingredientes 
ativos detectáveis, a maioria deles representada por resíduos de fungicidas. Os mesmos autores testaram o impacto desses compostos sobre a resistência de abelhas adultas à infecção por $N$. ceranae e verificaram que as abelhas que se alimentam com pólen contaminado são muito mais suscetíveis ao patógeno.

Além das rotas de exposição de contato e ingestão já mencionadas, o contato com a cera é outra rota de exposição aos agrotóxicos e tem sido negligenciada, o que pode induzir à interpretação errônea das causas de algumas perdas. Johnson et al. (2010) mostraram que os maiores resíduos nos produtos da colônia foram justamente encontrados na cera, mesmo em colônias localizadas em áreas distantes daquelas da aplicação. Segundo estes autores, uma das grandes suspeitas de mortalidade e, mais frequentemente, de morbidade, em colônias localizadas em áreas livres de aplicação de agrotóxicos, recai sobre a cera advinda de áreas em que as colônias estiveram expostas a tais produtos, pois esses, após troca e laminação da cera ali permanecem, mesmo que em concentrações mais baixas, em comparação àquelas obtidas de colônias expostas diretamente aos agrotóxicos. As amostras analisadas nos diferentes estudos relatados incluem resíduos em quantidades consideráveis das maiores classes de agrotóxicos. Além disso, os apicultores têm o hábito, principalmente no Brasil, de reutilizar favos nos diferentes ciclos de produção, o que aumentaria a exposição ao longo do tempo.

No entanto, não só as abelhas da espécie $A$. mellifera vêm sendo afetadas, esses efeitos têm sido registrados também quanto a outras espécies, tanto sociais quanto solitárias. De acordo com Feltham et al. (2014), inseticidas como o neonicotinoide imidacloprido podem afetar a eficiência da coleta de pólen de $B$. terrestris, se estas abelhas forem alimentadas com soluções de sacarose contendo o referido inseticida a $0,7 \mu \mathrm{g} \mathrm{kg}^{-1}$. Esta dose é similar à encontrada em canola (Bonmatin et al., 2003). O estudo mostrou que a eficiência da coleta de pólen por viagem pode cair até $30 \%$ em abelhas expostas, o que pode afetar a produção da rainha e ter impactos sobre a colônia. Estudos recentes mostraram que tanto $A$. mellifera quanto $B$. terrestris preferiram fontes de alimentos que continham neonicotinoides, $o$ que aumenta o risco de exposição e, consequentemente, de contaminação da colônia, uma vez que os estoques de pólen e néctar contaminados podem ser maiores do que aqueles sem contaminação (Kessler et al., 2015).
$\mathrm{Na}$ verdade, qualquer espécie de abelha que voe em áreas de cultivos que utilizem agrotóxicos terão seu desempenho prejudicado (Goulson, 2015).

No Brasil, a maior preocupação é em relação aos inseticidas, principalmente aqueles aplicados por aeronaves sobre as grandes extensões de monoculturas. De 2000 a 2012, as vendas de agrotóxicos no Brasil cresceram 194,09\% (Boletim de comercialização de agrotóxicos e afins, 2013). Só em 2013, foram vendidas 495.764,55 toneladas de ingredientes ativos, dos quais 11,5\% de substâncias com ação exclusivamente inseticida. Esse uso tem impactado sobre a diversidade de abelhas silvestres brasileiras, uma vez que muitas espécies de abelhas nativas têm se mostrado mais sensíveis do que a poli-híbrida A. mellifera africanizada.

Estudos comparativos sobre a suscetibilidade de espécies da fauna brasileira evidenciaram a alta toxicidade de diferentes ingredientes ativos para esse grupo de espécies: permetrina, heptacloro, dieldrina, cipermetrina, endossulfam, malationa, acetato, carbaril e fenvalerato para Trigona spinipes (Macieira \& Hebling-Beraldo, 1989); deltametrina, triclorfom e malationa para Scaptotrigona tubiba (Moraes et al., 2000); deltametrina e metamidofós para Melipona quadrifasciata (Del Sarto et al., 2014), imidacloprido para Melipona scutellaris (Costa et al., 2015) e Scaptotrigona postica (Soares et al., 2015); fipronil para M. scutellaris (Lourenço et al., 2012a, 2012b) e S. postica (Jacob et al., 2013). Muitos desses ingredientes ativos, durante sua rota metabólica, afetam diferentes processos celulares que impactam a longevidade, o comportamento e a fisiologia do inseto, e podem causar efeitos individuais e consequências para a colônia ao longo do tempo. Os dados mostram que eles podem afetar o processamento das informações no cérebro de $S$. postica e Melipona quadrifasciata (Jacob et al., 2015; Tomé et al., 2015). Há dados, inclusive, que mostram que produtos classificados como biopesticidas, como a azadiractina, podem causar deformações nas larvas e causar impactos sobre a manutenção do número de indivíduos da colônia (Barbosa et al., 2015).

Porém, os dados existentes não cobrem a diversidade de abelhas que ocorrem no Brasil - aproximadamente 1.700 espécies -, distribuídas em quase 300 gêneros (Moure et al., 2007). A depender do ecossistema considerado, essa diversidade é responsável pela 
polinização de 22 a $89 \%$ da flora nativa (Pinheiro et al., 2014). Além disso, só em 2012, foram comercializados produtos de 386 ingredientes ativos diferentes, nas mais diversas formulações (Boletim de comercialização de agrotóxicos e afins, 2013). Não há registros na literatura sobre a toxicidade da maioria desses ingredientes para as abelhas silvestres brasileiras, a não ser os dados de $\mathrm{DL}_{50}$ para $A$. mellifera exigidos para o registro do produto, que tem acesso restrito. Os dados sobre a suscetibilidade de abelhas solitárias a esses produtos são inexistentes. Diante desse cenário, são necessários estudos sobre a suscetibilidade das abelhas nativas, tanto sociais quanto solitárias, aos diferentes produtos usados hoje na agricultura brasileira. É óbvio que é impossível testar todos os ingredientes ativos, para todas as espécies de abelhas, mas é necessário que algumas espécies da fauna brasileira sejam escolhidas como modelo para essas avaliações. Ressalta-se, neste sentido, a importância de os bioensaios com A. mellifera serem realizados com colônias do biótipo brasileiro (A. mellifera africanizada). Deste modo, haverá informações que poderão fornecer subsídios, para que sejam desenvolvidos planos de manejo das culturas e medidas de mitigação mais adequadas às condições brasileiras.

\section{Mudanças climáticas}

Apis mellifera tem uma grande capacidade de se adaptar a diferentes condições climáticas e essa capacidade pode ser observada em sua ampla distribuição geográfica. Anecessidade de adaptação aos diversos ambientes e a pressão exercida pelo homem por um sistema cada vez mais produtivo têm provocado a constante adaptação desta espécie. Contudo, as elevadas taxas de mortalidade e a perda de colônias registradas recentemente, em nível mundial, mostram a fragilidade das populações manejadas de $A$. mellifera (Le Conte \& Navajas, 2008). O impacto das mudanças climáticas sobre as diferentes espécies de abelhas poderá ser observado em diversas avaliações, como: nas modificações do seu comportamento e fisiologia; na desestabilização das relações planta-polinizador, em razão da alteração do período de fornecimento de alimento; no aumento de competição intraespecífica por fontes de alimento e locais de nidificação; na migração e definição de novas áreas de distribuição; e na modificação das relações com os seus parasitas, agentes patogênicos e predadores (Le Conte \& Navajas, 2008; Reddy et al., 2012).
Para algumas espécies de abelhas, já existem evidências de alteração na distribuição geográfica. Por exemplo, algumas espécies do gênero Bombus na Europa e Estados Unidos têm migrado para regiões de maior altitude, que são mais frias (Kerr et al., 2015). Análises de cenário futuro sobre a distribuição geográfica de espécies do gênero Centris e Melipona, no Brasil, indicam que haverá uma redução das áreas de abrangência destas espécies até 2080, em comparação às projeções atuais (Giannini et al., 2015b).

A migração das abelhas e a modificação de suas distribuições geográficas favorecerá o contato com patógenos, parasitas e predadores com os quais elas não coexistiam anteriormente (Le Conte \& Navajas, 2008). As alterações do clima poderão, ainda, beneficiar ou estagnar a manifestação de algumas doenças que dependem de fatores climáticos para se manifestarem (Le Conte \& Navajas, 2008) e favorecer a instalação de espécies invasoras patogênicas, que migram em busca de condições mais adequadas para seu desenvolvimento. Além disso, microrganismos, parasitas e predadores que atualmente não são considerados como problemas podem modificar seu ciclo de desenvolvimento e ação e se tornar futuramente um problema sanitário (Reddy et al., 2012).

Para as abelhas, provavelmente, o maior impacto que as mudanças climáticas poderão causar se refere à extinção de espécies vegetais, alterações dos períodos de florescimento e a quantidade e qualidade de néctar e pólen (Reddy et al., 2012). O armazenamento de alimento é uma estratégia de sobrevivência para períodos com pouca disponibilidade de néctar e pólen (LeConte \& Navajas, 2008), pois, qualquer interferência sobre a quantidade de alimento disponível pode afetar o estado nutricional das colônias e, consequentemente, o sistema imunológico. As colônias que estiverem instaladas em apiários poderão, certamente, receber uma suplementação do apicultor, e os impactos deste problema poderão ser reduzidos. Contudo, as colônias que não estiverem recebendo um manejo adequado, a exemplo das colônias instaladas em matas e florestas ou de produtores menos cuidadosos, poderão sofrer um processo de desnutrição, ter sua resistência natural muito afetada e sofrer com ataques de inimigos naturais, infecções por patógenos ou infestações por parasitas, como é o caso do vírus Israeli acute paralysis (IAPV) e do ácaro $V$. destructor. Estas colônias, enfraquecidas, antes de serem naturalmente eliminadas, terão contribuído para a disseminação 
destes agentes patogênicos, inclusive os apontados como principais causadores da CCD.

Todos esses impactos afetarão as atividades que exploram comercialmente as abelhas, seja com seu serviço de polinização, seja com os produtos apícolas. As fronteiras da apicultura deverão ser alteradas em razão das mudanças climáticas e da disponibilidade de recurso florístico. Haverá também uma busca por subespécies mais resistentes e melhor adaptadas às novas condições ambientais (Le Conte \& Navajas, 2008). Neste sentido, o melhoramento genético e a conservação de germoplasma serão ferramentas fundamentais para a adaptação da atividade apícola a essa nova fase.

\section{Considerações finais}

Embora as causas da CCD ainda não estejam totalmente compreendidas, os esforços despendidos até o momento, principalmente nos EUA e na Europa, possibilitaram a geração de um volume considerável de informações sobre as possíveis ameaças bióticas e abióticas à saúde das abelhas. Importantes avanços científicos impulsionados, em especial, pelas ferramentas moleculares disponíveis, apontam para a impossibilidade de atribuir tais colapsos das colônias de abelhas melíferas a um único fator, exceto quando advindos de mortalidade aguda comprovadamente ocasionada por agrotóxicos. Assim, é fundamental elucidar os mecanismos de atuação das coinfecções e quais são os impactos dessas sobre o organismo das abelhas, além da necessidade de se conhecer a abundância, distribuição e diversidade genética dos organismos associados às abelhas, considerando-se o ambiente em que elas vivem e as interferências dos fatores externos (agrotóxicos, alimento e clima) nas interações abelhas-patógenos-parasitas.

As pesquisas que visam avaliar os impactos dos patógenos e parasitas sobre Apis mellifera africanizada e espécies silvestres, concomitantes aos efeitos de agrotóxicos usados na agricultura, precisam ser ampliadas e aprofundadas, na busca por respostas às perdas ou enfraquecimentos repentinos de colônias no País. Os referidos estudos, mesmo que escassos e restritos a determinadas regiões do Brasil, não apontam para evidências de envolvimentos isolados de patógenos com tal problemática. Quanto aos relatos de mortalidade, embora empíricos, por ausência de dados oficiais (o que só será possível com o envolvimento efetivo dos órgãos oficiais), muitos foram constatados in loco. As queixas por parte dos apicultores têm se tornado cada vez mais frequentes na última década. Casos com suspeita de envolvimento de agrotóxicos, mediante constatação de exacerbado número de abelhas adultas mortas dentro e fora das colmeias, foram presenciados por pesquisadores que conduziram os estudos ora apresentados. Considerando-se os conhecimentos acumulados em mais de dois séculos de estudos sobre patologia apícola em todo o mundo, sabe-se que nenhuma doença causa tal impacto, dessa forma tão aguda, senão intoxicações.

No Brasil, vários fatores contribuem para a atual falta de registros oficiais e o desconhecimento de moléculas possivelmente envolvidas nesses casos de perdas em massa de colônias. Entre vários fatores, podemos ressaltar: a falta de conhecimento por parte do apicultor sobre como agir diante do ocorrido (desconhecimento de como coletar as amostras e a que órgão reportar o fato); a escassez de laboratórios que adotem técnicas apropriadas à matriz em estudo (abelhas ou produtos apícolas oriundos das colmeias afetadas), suficientemente sensíveis para a detecção de concentrações que levem a tais danos; o exacerbado custo inerente às técnicas adotadas para análises de resíduos; e a característica da apicultura, em muitos casos, não ser a atividade principal do produtor, que gera dificuldade de coleta de amostras apropriadas em tempo hábil, na maioria dos casos (até 24 horas após o ocorrido).

Como o Brasil é reconhecidamente um grande consumidor mundial de agrotóxico e diante do conhecimento dos impactos negativos de muitas moléculas hoje utilizadas, cabem investigações e reflexões sobre as consequências de tais efeitos em longo prazo, não apenas em razão dos patógenos existentes e suas relações com o hospedeiro, mas também pelas relações destes compostos químicos com a microbiota natural do intestino das abelhas (reconhecidamente uma extensão do sistema imunológico), tanto na perspectiva individual como social (colônia). Perdura, ainda, a ausência na literatura de dados de avaliações de tais moléculas em campo ou semicampo, nas condições ambientais brasileiras, além de avaliações dos efeitos subletais em todas as fases de desenvolvimento das abelhas.

Enquanto não forem instituídas políticas públicas que visem contribuir com avaliações mais amplas da sanidade apícola, em território nacional, tanto por parte 
de órgãos regulamentadores de saúde animal, como por parte de agências de fomento à pesquisa, pouco se avançará nesta área do conhecimento. A criação de um fundo nacional fomentado pela iniciativa privada, porém gerido por agências públicas de pesquisa, pode ser uma saída para financiamentos de estudos que visem avaliar o efeito dos princípios ativos, em condições de campo e semicampo, além de avaliações de longo prazo.

Atualmente, os resultados obtidos são fruto de ensaios in vitro, que representam avanços de conhecimentos e, sem dúvida, já podem balizar decisões governamentais, mas que, por serem conduzidos em condições artificiais, devem ser levados a situações mais próximas das que ocorrem em campo. Levandose em conta o modelo agrícola praticado no país, experimentos que reflitam a realidade de campo são um desafio a mais a ser enfrentado pela pesquisa, já que diversos fatores devem ser avaliados em conjunto.

A situação da espécie $A$. mellifera e a CCD - em particular - têm chamado a atenção do mundo, precisamos, no entanto, ter a clareza de que alguns dos fatores que podem causar a CCD poderiam ser os mesmos que estão causando o declínio das populações e extinção das abelhas em geral, como: a incidência de pragas, parasitas e patógenos; a exposição a agrotóxicos; e a destruição e fragmentação de habitats, com a consequente redução de áreas de nidificação e forrageamento (Potts et al., 2010). No Brasil, essa situação é preocupante. Cerca de um terço do território nacional já foi convertido para a produção agrícola, o que tem levado à perda de grandes áreas de vegetação natural (Ferreira et al., 2012). Porém, os possíveis impactos da fragmentação de habitats sobre as comunidades de abelhas, associados às práticas agrícolas, não têm sido devidamente avaliados.

\section{Referências}

AHN, K.; XIE, X.; RIDDLE, J.; PETTIS, J.; HUANG, Z.Y. Effects of long distance transportation on honey bee physiology. Psyche: a Journal of Entomology, v.2012, article ID 193029, 2012. DOI: $10.1155 / 2012 / 193029$.

ALAUX, C.; DANTEC, C.; PARRINELLO, H.; LE CONTE, Y. Nutrigenomics in honey bees: digital gene expression analysis of pollen's nutritive effects on healthy and varroa-parasitized bees. BMC Genomics, v.12, 2011. DOI: 10.1186/1471-2164-12-496.
ANDI, M.A.; AHMADI, A. Influence of vitamin C in sugar syrup on brood area, colony population, body weight and protein in honey bees. International Journal of Biosciences, v.4, p.32-36, 2014.

ARONSTEIN, K.A.; SALDIVAR, E.; VEGA, R.; WESTMILLER, S.; DOUGLAS, A.E. How Varroa parasitism affects the immunological and nutritional status of the honey bee, Apis mellifera. Insects, v.3, p.601-615, 2012. DOI: 10.3390/ insects3030601.

BAILEY, L.; BALL, B.V. Honey bee pathology. London: Academic Press, 1991. 208p.

BALBUENA, M.S.; TISON, L.; HAHN, M.-L.; GREGGERS, U.; MENZEL, R.; FARINA, W.M. Effects of sublethal doses of glyphosate on honeybee navigation. Journal of Experimental Biology, v.218, p.2799-2805, 2015. DOI: 10.1242/jeb.117291.

BARBOSA, W.F.; TOMÉ, H.V.V.; BERNARDES, R.C.; SIQUEIRA, M.A.L.; SMAGGHE, G.; GUEDES, R.N.C. Biopesticide-induced behavioral and morphological alterations in the stingless bee Melipona quadrifasciata. Environmental Toxicology and Chemistry, v.34, p.2149-2158, 2015. DOI: 10.1002/etc.3053.

BAYLOR COLLEGE OF MEDICINE HUMAN GENOME SEQUENCING CENTER. Baylor College of Medicine Human Genome Sequencing Center. Available at: $<$ https://www.hgsc. bcm.edu/>. Accessed on: 28 Aug. 2015.

BOLETIM de comercialização de agrotóxicos e afins: histórico de vendas - 2000 a 2012. Brasília: Instituto Brasileiro do Meio Ambiente e dos Recursos Naturais Renováveis, 2013. 42p.

BONMATIN, J.M.; MOINEAU, I.; CHARVET, R.; FLECHE, C.; COLIN, M.E.; BENGSCH, E.R. A LC/APCI-MS/MS method for analysis of imidacloprid in soils, in plants, and in pollens. Analytical Chemistry, v.75, p.2027-2033, 2003. DOI: 10.1021/ ac020600b.

BRODSCHNEIDER, R.; CRAILSHEIM, K. Nutrition and health in honey bees. Apidologie, v.41, p.278-294, 2010. DOI: 10.1051/ apido/2010012.

BROMENSHENK, J.J.; HENDERSON, C.B.; WICK, C.H.; STANFORD, M.F.; ZULICH, A.; JABBOUR, R.E.; DESHPANDE, S.V.; MCCUBBIN, P.E.; SECCOMB, R.A.; WELCH, P.M.; WILLIAMS, T.; FIRTH, D.R.; SKOWRONSKI, E.; LEHMANN, M.M.; BILIMORIA, S.L.; GRESS, J.; WANNER, K.W.; CRAMER JR., R.A. Iridovirus and microsporidian linked to honey bee colony decline. Plos One, v.5, e13181, 2010. DOI: 10.1371/journal.pone.0013181.

BUDGE, G.E.; GARTHWAITE, D.; CROWE, A.; BOATMAN, N.D.; DELAPLANE, K.S.; BROWN, M.A.; THYGESEN, H.H.; PIETRAVALLE, S. Evidence for pollinator cost and farming benefits of neonicotinoid seed coatings on oilseed rape. Scientific Reports, v.5, Article number 12574, 2015. DOI: 10.1038/ srep12574.

CARVALHO, A.C.P. de; MESSAGE, D. A scientific note on the toxic pollen of Stryphnodendron polyphyllum (Fabaceae, Mimosoideae) with causes sacbrood-like symptoms. Apidologie, v.35, p.89-90, 2004. DOI: 10.1051/apido:2003059. 
CASTAGNINO, G.L.B.; MESSAGE, D.; MARCO JÚNIOR, P. de. Fornecimento de substituto de pólen na redução da mortalidade de Apis mellifera L. causada pela cria ensacada brasileira. Ciência Rural, v.41, p.1838-1843, 2011. DOI: 10.1590/ S0103-84782011001000027.

CHAUZAT, M.-P.; MARTEL, A.-C.; ZEGGANE, S.; DRAJNUDEL, P.; SCHURR, F.; CLÉMENT, M.-C.; RIBIÈRE-CHABERT, M.; AUBERT, M.; FAUCON, J.-P. A case control study and a survey on mortalities of honey bee colonies (Apis mellifera) in France during the winter of 2005-6. Journal of Apicultural Research, v.49, p.40-51, 2010. DOI: 10.3896/ IBRA.1.49.1.06.

CHEN, Y.P.; PETTIS, J.S.; CORONA, M.; CHEN, W.P.; LI, C.J.; SPIVAK, M.; VISSCHER, P.K.; DeGRANDI-HOFFMAN, G.; BONCRISTIANI, H.; ZHAO, Y.; vanENGELSDORP, D.; DELAPLANE, K.; SOLTER, L.; DRUMMOND, F.; KRAMER, M.; LIPKIN, W.I.; PALACIOS, G.; HAMILTON, M.C.; SMITH, B.; HUANG, S.K.; ZHENG, H.Q.; LI, J.L.; ZHANG, X.; ZHOU, A.F.; WU, L.Y.; ZHOU, J.Z.; LEE, M.-L.; TEIXEIRA, E.W.; LI, Z.G.; EVANS, J.D. Israeli Acute Paralysis Virus: epidemiology, pathogenesis and implications for honey bee health. Plos Pathogens, v.10, e1004261, 2014. DOI: 10.1371/journal. ppat.1004261

CLARK, T.B. Spiroplasma sp., a new pathogen in honey bees. Journal of Invertebrate Pathology, v.29, p.112-113, 1977. DOI: 10.1016/0022-2011(77)90181-1.

COLONY COLLAPSE DISORDER. Colony collapse disorder action plan. Available at: $<$ http://www.ars.usda.gov/is/br/ccd/ccd actionplan.pdf $>$. Accessed on: 28 Aug. 2015.

COLOSS. Coloss honey bee research association. Available at: $<$ http://www.coloss.org/>. Accessed on: 28 Aug. 2015a.

COLOSS. Coloss honey bee research association: publications. Available at: $<$ http://www.coloss.org/publications $>$. Accessed on: 28 Aug. 2015b.

CORNMAN, R.S.; TARPY, D.R.; CHEN, Y.; JEFFREYS, L.; LOPEZ, D.; PETTIS, J.S.; vanENGELSDORP, D.; EVANS, J.D. Pathogen webs in collapsing honey bee colonies. PLoS ONE, v.7, e43562, 2012. DOI: 10.1371/journal.pone.0043562.

COSTA, L.M.; GRELLA, T.C.; BARBOSA, R.A.; MALASPINA, O.; NOCELLI, R.C.F. Determination of acute lethal doses (LD50 and LC50) of imidacloprid for the native bee Melipona scutellaris Latreille, 1811 (Hymenoptera: Apidae). Sociobiology, v.62, p.578-552, 2015. DOI: 10.13102/sociobiology.v62i4.792.

COTTER, S.C.; SIMPSON, S.J.; RAUBENHEIMER, S.S.; WILSON, D.K. Macronutrient balance mediates trade-offs between immune function and life history traits. Functional Ecology, v.25, p.186-198, 2011.

COX-FOSTER, D.L.; CONLAN, S.; HOLMES, E.C.; PALACIOS, G.; EVANS, J.D.; MORAN, N.A.; QUAN, P.; BRIESE, T.; HORNIG, M.; GEISER, D.M.; MARTINSON, V.; vanENGELSDORP, D.; KALKSTEIN, A.L.; DRYSDALE, A.; HUI, J.; ZHAI, J.; CUI, L.; HUTCHISON, S.K.; SIMONS, J.F.; EGHOLM, M.; PETTIS, J.S.; LIPKIN, W.I. A metagenomic survey of microbes in honey bee colony collapse disorder. Science, v.318, p.283-287, 2007. DOI: 10.1126/science.1146498.
CUTLER, G.C.; SCOTT-DUPREE, C.D.; SULTAN, M.; MCFARLANE, A.D.; BREWER, L. A large-scale field study examining effects of exposure to clothianidin seed-treated canola on honey bee colony health, development, and overwintering success. Peer J, v.2, e652, 2014. DOI: 10.7717/peerj.652. eCollection 2014.

DADD, R.H. Insect nutrition: current developments and metabolic implications. Annual Review of Entomology, v.18, p.381-420, 1973. DOI: 10.1146/annurev.en.18.010173.002121.

DE GROOT, A.P. Protein and amino acid requirements of the honeybee (Apis mellifera L.). 1953. Available at: $<$ http://194.47.52.113/janlars/partnerskapalnarp/ekonf/20130516/ deGroot1953.pdf>. Accessed on: 28 Aug. 2015.

DE JONG, D.; MORSE, R.A.; EICKWORT, G.C. Mite pests of honey bees. Annual Review of Entomology, v.27, p.229-252, 1982. DOI: 10.1146/annurev.en.27.010182.001305.

DECOURTYE, A.; CÉDRIC, A.; ODOUX, J.-F.; MICKAËL, H.; VAISSIÈRE, B.E.; LE CONTE, Y. Why enhancement of floral resources in agro-ecosystems benefit honeybees and beekeepers? In: GRILLO, O.; VENORA, G. (Ed.). Ecosystems biodiversity. Rijeka: InTech, 2001. p.371-388. DOI: 10.5772/24523.

DECOURTYE, A.; DEVILLERS, J.; CLUZEAU, S.; CHARRENTON, M.; PHAM-DELÈGUE, M.-H. Effects of imidacloprid and deltamethrin on associative learning in honeybees under semi-field and laboratory conditions. Ecotoxicology and Environmental Safety, v.57, p.410-419, 2004. DOI: $10.1016 /$ j. ecoenv.2003.08.001

DeGRANDI-HOFFMAN, G.; CHEN, Y. Nutrition, immunity and viral infections in honey bees. Current Opinion in Insect Science, v.10, p.170-176, 2015. DOI: 10.1016/j.cois.2015.05.007.

DEL SARTO, M.C.L.; OLIVEIRA, E.E.; GUEDES, R.N.C.; CAMPOS, L.A.O. Differential insecticide susceptibility of the Neotropical stingless bee Melipona quadrifasciata and the honey bee Apis mellifera. Apidologie, v.45, p.626-636, 2014. DOI: 10.1007/s13592-014-0281-6.

DIVELY, G.P.; EMBREY, M.S.; KAMEL, A.; HAWTHORNE, D.J.; PETTIS, J.S. Assessment of chronic sublethal effects of imidacloprid on honey bee colony health. PLoS ONE, v.10, e0118748, 2015. DOI: 10.1371/journal.pone.0118748.

DIVELY, G.P.; KAMEL, A. Insecticide residues in pollen and nectar of a cucurbit crop and their potential exposure to pollinators. Journal of Agricultural and Food Chemistry, v.60, p.4449-4456, 2012. DOI: 10.1021/jf205393x.

DONKERSLEY, P.; RHODES, G.; PICKUP, R.W.; JONES, K.C.; WILSON, K. Honeybee nutrition is linked to landscape composition. Ecology and Evolution, v.4, p.4195-4206, 2014. DOI: $10.1002 /$ ece3.1293.

DOUBLET, V.; LABARUSSIAS, M.; MIRANDA, J.R. de; MORITZ, R.F.A.; PAXTON, R.J. Bees under stress: sublethal doses of a neonicotinoid pesticide and pathogens interact to elevate honey bee mortality across the life cycle. Environmental Microbiology, v.17, p.969-983, 2015. DOI: 10.1111/1462-2920.12426.

EVANS, J.D. Beepath: an ordered quantitative-PCR array for exploring honey bee immunity and disease. Journal of 
Invertebrate Pathology, v.93, p.135-139, 2006. DOI: 10.1016/j. jip.2006.04.004.

EVANS, J.D.; SPIVAK, M. Socialized medicine: individual and communal disease barriers in honey bees. Journal of Invertebrate Pathology, v.103, p.S62-S72, 2010. DOI: 10.1016/j. jip.2009.06.019.

FELTHAM, H.; PARK, K.; GOULSON, D. Field realistic doses of pesticide imidacloprid reduce bumblebee pollen foraging efficiency. Ecotoxicology, v.23, p.317-323, 2014. DOI: 10.1007/ s10646-014-1189-7.

FERREIRA, J.; PARDINI, R.; METZGER, J.P.; FONSECA, C.R.; POMPEU, P.S.; SPAROVEK, G.; LOUZADA, J. Towards environmentally sustainable agriculture in Brazil, challenges and opportunities for applied ecological research. Journal of Applied Ecology, v. 49, p.535-541, 2012. DOI: 10.1111/j.1365-2664.2012 $.02145 . x$.

FRAZIER, M.; MULLIN, C.; FRAZIER, J.; ASHCRAFT, S. What have pesticides got to do with it? American Bee Journal, v.148, p.521-523, 2008.

FRIAS, B.E.D.; BARBOSA, C.D.; LOURENÇO A.P. Pollen nutrition in honey bees (Apis mellifera): impact on adult health. Apidologie, v.47, p.15-25, 2015. DOI: 10.1007/s13592-0150373-y.

GALLAI, N.; SALLES, J.-M.; SETTELE, S.; VAISSIÈRE, B.E. Economic valuation of the vulnerability of world agriculture confronted with pollinator decline. Ecological Economics, v.68, p.810-821, 2009. DOI: 10.1016/j.ecolecon.2008.06.014.

GARIBALDI, L.A.; STEFFAN-DEWENTER, I.; KREMEN, C.; MORALES, J.M.; BOMMARCO, R.; CUNNINGHAM, S.A.; CARVALHEIRO, L.G.; CHACOFF, N.P.; DUDENHÖFFER, J.H.; GREENLEAF, S.S.; HOLZSCHUH, A.; ISAACS, R.; KREWENKA, K.; MANDELIK, Y.; MAYFIELD, M.M.; MORANDIN, L.A.; POTTS, S.G.; RICKETTS, T.H.; SZENTGYÖRGYI, H.; VIANA, B.F.; WESTPHAL, C.; WINFREE, R.; KLEIN, A.M. Stability of pollination services decreases with isolation from natural areas despite honey bee visits. Ecology Letters, v.14, p.1062-1072, 2011. DOI: 10.1111/j.1 461-0248.2011.01669.x.

GARIBALDI, L.A.; STEFFAN-DEWENTER, I.; WINFREE, R.; AIZEN, M.A.; BOMMARCO, R.; CUNNINGHAM, S.A.; KREMEN, C.; CARVALHEIRO, L.G.; HARDER, L.D.; AFIK, O.; BARTOMEUS, I.; BENJAMIN, F.; BOREUX, V.; CARIVEAU, D.; CHACOFF, N.P.; DUDENHÖFFER, J.H.; FREITAS, B.M.; GHAZOUL, J.; GREENLEAF, S.; HIPÓLITO, J.; HOLZSCHUH, A.; HOWLETT, B.; ISAACS, R.; JAVOREK, S.K.; KENNEDY, C.M.; KREWENKA, K.M.; KRISHNAN, S.; MANDELIK, Y.; MAYFIELD, M.M.; MOTZKE, I.; MUNYULI, T.; NAULT, B.A.; OTIENO, M.; PETERSEN, J.; PISANTY, G.; POTTS, S.G.; ROMINA RADER, R.; RICKETTS, T.H.; RUNDLÖF, M.; SEYMOUR, C.L.; SCHÜEPP, C.; SZENTGYÖRGYI, H.; TAKI, H.; TSCHARNTKE, T.; VERGARA, C.H.; VIANA, B.F.; WANGER, T.C.; WESTPHAL, C.; WILLIAMS, N.; KLEIN, A.M. Wild pollinators enhance fruit set of crops regardless of honey bee abundance. Science, v.339, p.1608-1611, 2013. DOI: 10.1126/ science. 1230200 .
GENERSCH, E.; OHE, W. von der; KAATZ, H.; SCHROEDER, A.; OTTEN, C.; BÜCHLER, R.; BERG, S.; RITTER, W.; MÜLHEN, W.; GISDER, S.; MEIXNER, M.; LIEBIG, G.; ROSENKRANZ, P. The German bee monitoring project: a long term study to understand periodically high winter losses of honeybee colonies. Apidologie, v.41, p.332-352, 2010. DOI: 10.1051/apido/2010014.

GIANNINI, T.C.; CORDEIRO, G.D.; FREITAS, B.M.; SARAIVA, A.M.; IMPERATRIZ-FONSECA, V.L. The dependence of crops for pollinators and the economic value of pollination in Brazil. Journal of Economic Entomology, v.108, p.1-9, 2015a. DOI: 10.1093/jee/tov093.

GIANNINI, T.C.; TAMBOSI, L.R.; ACOSTA, A.L.; JAFFÉ, R.; SARAIVA, A.M.; IMPERATRIZ-FONSECA, V.L.; METZGER, J.P. Safeguarding ecosystem services: a methodological framework to buffer the joint effect of habitat configuration and climate change. PLoS ONE, v.10, e0129225, 2015b. DOI: 10.1371/ journal.pone.0129225.

GODFRAY, H.C.J.; BLACQUIÈRE, T.; FIELD, L.M.; HAILS, R.S.; PETROKOFSKY, G.; POTTS, S.G.; MCLEAN, A.R. A restatement of the natural science evidence base concerning neonicotinoid insecticides and insect pollinators. Proceedings of the Royal Society B: Biological Sciences, v.281, 2014. DOI: 10.1098/rspb.2014.0558.

GONÇALVES, L.S. O desaparecimento das abelhas, suas causas, consequências e o risco dos neonicotinoides para o agronegócio apícola. Mensagem Doce, v.117, p.2-12, 2012.

GOULSON, D. Neonicotinoids impact bumblebee colony fitness in the field: a reanalysis of the UK's Food \& Environment Research Agency 2012 experiment. Peer J, v.3, e854, 2015. DOI: 10.7717/ peerj.854.

HADDAD, N. Honey bee viruses, diseases and hive management in the Middle East and their relation to the colony collapse disorder and bee losses. Uludag Bee Journal, v.11, p.17-24, 2011.

HERBERT, L.T.; VÁZQUEZ, D.E.; ARENAS, A.; FARINA, W.M. Effects of field-realistic doses of glyphosate on honeybee appetitive behaviour. Journal of Experimental Biology, v.217, p.3457-3464, 2014. DOI: 10.1242/jeb.109520.

HOLANDA-NETO, J.P. de; PAIVA, C. da S.; MELO, S.B. de; PAIVA, A.C.C. de; MARACAJÁ, P.B.; SILVA, A.F. da; PEREIRA, D.S. Comportamento de abandono de abelhas africanizadas em apiários durante a entressafra, na região do Alto Oeste Potiguar, Brasil. Agropecuária Científica no Semiárido, v.11, p.77-85, 2015.

JACOB, C.R.O.; SOARES, H.M.; CARVALHO, S.M.; NOCELLI, R.C.F.; MALASPINA, O. Acute toxicity of fipronil to the stingless bee Scaptotrigona postica Latreille. Bulletin of Environmental Contamination and Toxicology, v.90, p.69-72, 2013. DOI: 10.1007/s00128-012-0892-4.

JACOB， C.R.O.; SOARES， H.M.; NOCELLI, R.C.F.; MALASPINA, O. Impact of fipronil on the mushroom bodies of the stingless bee Scaptotrigona postica. Pest Management Science, v.71, p.114-122, 2015. DOI: 10.1002/ps.3776.

JAFFÉ, R.; POPE, N.; CARVALHO, A.T.; MAIA, U.M.; BLOCHTEIN, B.; CARVALHO, C.A.L. de; CARVALHO-ZILSE, G.A.; FREITAS, B.M.; MENEZES, C.; RIBEIRO, M. de F.; 
VENTURIERI, G.C.; IMPERATRIZ-FONSECA, V.L. Bees for development: Brazilian survey reveals how to optimize stingless beekeeping. PLoS ONE, v.10, e0121157, 2015. DOI: 10.1371/ journal.pone.0121157.

JOHNSON, R.M.; ELLIS, M.D.; MULLIN, C.A.; FRAZIER, M. Pesticides and honey bee toxicity - USA. Apidologie, v.41, p.312-331, 2010. DOI: 10.1051/apido/2010018.

KERR, J.T.; PINDAR, A.; GALPERN, P.; PACKER, L.; POTTS, S.G.; ROBERTS, S.M.; RASMONT, P.; SCHWEIGER, O.; COLLA, S.R.; RICHARDSON, L.L.; WAGNER, D.L.; GALL, L.F.; SIKES, D.S.; PANTOJA, A. Climate change impacts on bumblebees converge across continents. Science, v.349, p.177-180, 2015. DOI: 10.1126/science.aaa7031.

KESSLER, S.C.; TIEDEKEN, E.J.; SIMCOCK, K.L; DERVEAU, S.; MITCHELL, J.; SOFTLEY, S.; RADCLIFFE, A.; STOUT, J.C.; WRIGHT, G.A. Bees prefer foods containing neonicotinoid pesticides. Nature, v.521, p.74-76, 2015. DOI: 10.1038/ nature14414.

KLEE, J.; BESANA, A.M.; GENERSCH, E.; GISDER, S.; NANETTI, A.; TAM, D.Q.; CHINH, T.X.; PUERTA, F.; RUZ, J.M.; KRYGER, P.; MESSAGE, D.; HATJINA, F.; KORPELA, S.; FRIES, I.; PAXTON, R.J. Widespread dispersal of the microsporidian Nosema ceranae, an emergent pathogen of the western honey bee, Apis mellifera. Journal of Invertebrate Pathology, v.96, p.1-10, 2007. DOI: 10.1016/j.jip.2007.02.014.

KLEIN, A.-M.; VAISSIÈRE, B.E.; CANE, J.H.; STEFFAN-DEWENTER, I.; CUNNINGHAM, S.A.; KREMEN, C.; TSCHARNTKE, T. Importance of pollinators in changing landscapes for world crops. Proceedings of the Royal Society B, v.274, p.303-313, 2007. DOI: 10.1098/rspb.2006.3721.

LAURENT, M.; HENDRIKX, P.; RIBIERE-CHABERT, M.; CHAUZAT, M.-P. A pan-European epidemiological study on honeybee colony losses 2012-2014. 2015. Available at: $<$ http://ec.europa.eu/food/animals/live_animals/bees/docs/ bee-report_2012_2014_en.pdf $>$. Accessed on: 28 Aug. 2015.

LE CONTE, I.; NAVAJAS, M. Climate change: impact on honey bee populations and diseases. Revue Scientifique et Technique, v.27, p.499-510, 2008.

LEE, K.V.; STEINHAUER, N.; RENNICH, K.; WILSON, M.E.; TARPY, D.R.; CARON, D.M.; ROSE, R.; DELAPLANE, K.S.; BAYLIS, K.; LENGERICH, E.J.; PETTIS, J.; SKINNER, J.A.; WILKES, J.T.; SAGILI, R. ; vanENGELSDORP, D. A national survey of managed honey bee 2013-2014 annual colony losses in the USA. Apidologie, v.46, p.292-305, 2015. DOI: 10.1007/ s13592-015-0356-z.

LOURENÇO, C.T.; CARVALHO, S.M.; MALASPINA, O.; NOCELLI, R.C.F. Determination of fipronil $\mathrm{LD}_{50}$ for the Brazilian bee Melipona scutellaris. Julius Kühn-Institute, v.437, p.174-178, 2012a. DOI: 10.5073/jka.2012.437.046.

LOURENÇO, C.T.; CARVALHO, S.M.; MALASPINA, O.; NOCELLI, R.C.F. Oral toxicity of fipronil insecticide against the stingless bee Melipona scutellaris (Latreille, 1811). Bulletin of Environmental Contamination and Toxicology, v.89, p.921-924, 2012b. DOI: 10.1007/s00128-012-0773-x.
MACIEIRA, O.J.D.; HEBLING-BERALDO, M.J.A. Laboratory toxicity of insecticides to workers of Trigona spinipes (F., 1793) (Hymenoptera, Apidae). Journal of Apicultural Research, v.28, p.3-6, 1989. DOI: 10.1080/00218839.1989.11100813.

MARTÍN-HERNÁNDEZ, R.; MEANA, A.; PRIETO, L.; SALVADOR, A.M.; GARRIDO-BAILÓN, E.; HIGES, M. Outcome of colonization of Apis mellifera by Nosema ceranae. Applied and Environmental Microbiology, v.73, p.6331-6338, 2007. DOI: 10.1128/AEM.00270-07.

MESSAGE, D.; TEIXEIRA, É.W.; DE JONG, D. Situação da sanidade das abelhas no Brasil. In: FONSECA, V.L.I.; CANHPS, D.A.L.; ALVES, D. de A.; SARAIVA, A.M. (Org.). Polinizadores no Brasil: contribuição e perspectivas para a biodiversidade, uso sustentável, conservação e serviços ambientais. São Paulo: Edusp, 2012. p.237-256

MIRANDA, J.R. de; CORNMAN, R.S.; EVANS, J.D.; SEMBERG, E.; HADDAD, N.; NEUMANN, P.; GAUTHIER, L. Genome characterization, prevalence and distribution of a Macula-Like Virus from Apis mellifera and Varroa destructor. Viruses, v.7, p.3586-3602, 2015. DOI: 10.3390/v7072789.

MIRANDA, J.R.; GAUTHIER, L.; RIBIÈRE, M.; CHEN, Y.P. Honey bee viruses and their effect on bee and colony health. In: SAMMATARO, D.; YODER, J.A. (Ed.). Honey bee colony health: challenges and sustainable solutions. Boca Raton: CRC Press, 2012. p.71-102.

MITIDIERO, A.M. de A. Defesa sanitária animal: sanidade das abelhas. 2013. Disponível em: <http://www.cidasc.sc.gov.br/ defesasanitariaanimal/programas/sanidade-apicola/>. Acesso em: 28 ago. 2015.

MORAES, S.S.; BAUTISTA, A.R.L.; VIANA, B.F. Avaliação da toxicidade aguda (DL50 e CL50) de inseticidas para Scaptotrigona tubiba (Smith) (Hymenoptera: Apidae): via de contato. Anais da Sociedade Entomológica Brasil, v.29, p.31-37, 2000.

MOURE, J.M.; URBAN, D.; MELO, G.A.R. Catalogue of bees (Hymenoptera, Apoidea) in the Neotropical region. Curitiba: Sociedade Brasileira de Entomologia, 2007. 1058p.

MULLIN, C.A.; FRAZIER, M.; FRAZIER, J.L.; ASHCRAFT, S.; SIMONDS, R.; vanENGELSDORP, D.; PETTIS, J.S. High levels of miticides and agrochemicals in North American apiaries: implications for honey bee health. PLoS One, v.5, e9754, 2010. DOI: 10.1371/journal.pone.0009754.

PAXTON, R.J. Does infection by Nosema ceranae cause "colony collapse disorder" in honey bees (Apis mellifera)? Journal of Apicultural Research, v.49, p.80-84, 2010. DOI: 10.3896/ IBRA.1.49.1.11.

PEREIRA, F. de M.; FREITAS, B.M.; LOPES, M.T. do R. Nutrição e alimentação das abelhas. Teresina: Embrapa Meio-Norte, 2011. $113 \mathrm{p}$.

PETTIS, J.S.; DELAPLANE, K. Coordinated responses to honey bee decline in the USA. Apidologie, v.41, p.256-263, 2010. DOI: 10.1051/apido/2010013.

PETTIS, J.S.; LICHTENBERG, E.M.; ANDREE, M.; STITZINGER, J.; ROSE, R.; vanENGELSDORP, D. Crop pollination exposes honey bees to pesticides which alters their 
susceptibility to the gut pathogen Nosema ceranae. PLoS One, v.8, e70182, 2013. DOI: 10.1371/journal.pone.0070182.

PILlING, E.; CAMPBELL, P.; COULSON, M.; RUDDLE, N.; TORNIER, I. A four-year field program investigating long-term effects of repeated exposure of honey bee colonies to flowering crops treated with thiamethoxam. PLOs One, v.8, 2013. DOI: 10.1371/journal.pone.0077193.

PINHEIRO, M.; GAGLIANONE, M.C.; NUNES, C.E.P.; SIGRIST, M.R.; SANTOS, I.A. dos. Polinização por abelhas. In: RECH, A.R.; AGOSTINI, K.; OLIVEIRA, P.E.; MACHADO, I.C. (Org.). Biologia da Polinização. Rio de Janeiro: Projeto Cultural, 2014. p.205-233.

POTTS, S.G.; BIESMEIJER, J.C.; KREMEN, C.; NEUMANN, P.; SCHWEIGER, O.; KUNIN, W.E. Global pollinator declines: trends, impacts and drivers. Trends in Ecology and Evolution, v.25, p.345-353, 2010. DOI: 10.1016/j.tree.2010.01.007.

PRODUÇÃO DA PECUÁRIA MUNICIPAL. Rio de Janeiro: IBGE, v.42, 2014. 39p.

REDDY, P.V.R.; VERGHESE, A.; RAJAN, V.V. Potential impact of climate change on honeybees (Apis spp.) and their pollination services. Pest Management in Horticultural Ecosystems, v.18, p.121-127, 2012.

ROSENKRANZ, P. Honey bee (Apis mellifera L.) tolerance to Varroa jacobsoni Oud. in South America. Apidologie, v.30, p.159-172, 1999. DOI: 10.1051/apido:19990206.

RUNDLÖF, M.; ANDERSSON, G.K.S.; BOMMARCO, R.; FRIES, I.; HEDERSTRÖM, V.; HERBERTSSON, L.; JONSSON, O.; KLATT, B.K.; PEDERSEN, T.R.; YOURSTONE, J.; SMITH, H.G. Seed coating with a neonicotinoid insecticide negatively affects wild bees. Nature, v.521, p.77-80, 2015. DOI: 10.1038/ nature 14420 .

SANDROCK, C.; TANADINI, M.; TANADINI, L.G.; FAUSER-MISSLIN, A.; POTTS, S.G.; NEUMANN, P. Impact of chronic neonicotinoid exposure on honeybee colony performance and queen supersedure. PloS One, v.9, e103592, 2014. DOI: 10.1371/journal.pone.0103592.

SANTOS, L.G.; ALVES, M.L.T.M.F.; MESSAGE, D.; PINTO, F. de A.; SILVA, M.V.G.B. da; TEIXEIRA, É.W. Bee health in apiaries in the Paraíba Valley, São Paulo state, Southeast Brazil. Sociobiology, v.61, p.307-312, 2014. DOI: 10.13102/sociobiology. v61i3.307-312.

SCHMUCK, R.; NAUEN, R.; EBBINGHAUS-KINTSCHER, U. Effects of imidacloprid and common plant metabolites of imidacloprid in the honeybee: toxicological an biochemical considerations. Bulletin of Insectology, v.56, p.27-34, 2001.

SCHNEIDER, C.W.; TAUTZ, J.; GRÜNEWALD, B.; FUCHS, S. RFID tracking of sublethal effects of two neonicotinoid insecticides on the foraging behavior of Apis mellifera. PloS One, v.7, e30023, 2012. DOI: 10.1371/journal.pone.0030023.

SCHNEIDER, S.S.; DeGRANDI-HOFFMAN, G.; SMITH, D.R. The African honey bee: factors contributing to a successful biological invasion. Annual Review of Entomology, v.49, p.351-376, 2004. DOI: 10.1146/annurev.ento.49.061802.123359.
SCHWARZ, R.S.; TEIXEIRA, E.W.; TAUBER, J.P.; BIRKE, J.M.; MARTINS, M.F.; FONSECA, I.; EVANS, J.D. Honey bee coolies act as reservoirs for two Spiroplasma facultative symbionts and incur complex, multiyear infection dynamics. Microbiology Open, v.3, p.341-355, 2014. DOI: 10.1002/mbo3.172.

SOARES, H.M.; JACOB, C.R.O.; CARVALHO, S.M.; NOCELLI, R.C.F.; MALASPINA, O. Toxicity of imidacloprid to the stingless bee Scaptotrigona postica Latreille, 1807 (Hymenoptera: Apidae). Bulletin of Environmental Contamination and Toxicology, v.94, p.675-680, 2015. DOI: 10.1007/ s00128-015-1488-6.

SOUZA, E.A. de; VAZ, R. da S.; SILVA, F.E.J. da; PEREIRA, D.S.; HOLANDA NETO, J.P. de. Nível tecnológico empregado no manejo para produção de mel de Apis mellifera L. em três municípios do Alto Oeste Potiguar. ACTA Apicola Brasilica, v.2, p.16-23, 2014. DOI: 10.18378/aab.v2i1.3158.

STRAPAZZON, R.; CARNEIRO, F.E.; GUERRA JR, J.C.V.; MORETTO, G. Genetic characterization of the mite Varroa destructor (Acari: Varroidae) collected from honey bees Apis mellifera (Hymenoptera, Apidae) in the state of Santa Catarina, Brazil. Genetics and Molecular Research, v.8, p.990-997, 2009. DOI: $10.4238 /$ vol8-3gmr567.

SUCHAIL, S.; GUEZ, D.; BELZUNCES, L.P. Toxicity of imidacloprid and its metabolites in Apis mellifera. Colloques de I'INRA, v.98, 121-126, 2001.

SUMPTER, D.J.T.; MARTIN, S.J. The dynamics virus epidemics in Varroa-infested honey bee colonies. Journal of Animal Ecology, v.73, p.51-63, 2004. DOI: 10.1111/j.1365-2656.2004.00776.x.

SZCZESNA,T.; RYBAK-CHMIELEWSKA,H.; CHMIELEWSKI, W. Sugar composition of pollen loads harvested at different periods of the beekeeping season. Journal of Apicultural Science, v.46, p.107-115, 2002.

TEIXEIRA, É.W. Ocorrência de larvas de Leptus sp. Latreille 1796 (Acarina: Erythraeidae) em operárias de abelhas africanizadas A. mellifera Linnaeus 1758 (Hymenoptera: Apidae), no Brasil. Boletim da Indústria Animal, v.65, p.349-351, 2008.

TEIXEIRA, E.W.; CHEN, Y.; MESSAGE, D.; PETTIS, J.; EVANS, J.D. Virus infection in Brazilian honey bees. Journal of Invertebrate Pathology, v.99, p.117-119, 2008a. DOI: 10.1016/j. jip.2008.03.014.

TEIXEIRA, E.W.; CHEN, Y.-P.; MESSAGE, D.; BONCRISTIANI, H.F.; PETTIS, J.S.; EVANS, J.D. Israeli acute paralysis virus in Africanized honey bees in southeastern Brazilian apiaries. Journal of Apicultural Research, v.51, p.282-284, 2012. DOI: 10.3896/ IBRA.1.51.3.11.

TEIXEIRA, E.W.; MESSAGE, D.; CHEN, Y.; PETTIS, J.; EVANS, J.D. First metagenomic analysis of microorganisms in honey bees from Brazil. Boletim da Indústria Animal, v.65, p.355-361, 2008b.

TEIXEIRA, É.W.; SANTOS, L.G. dos; MATIOLI, A.L.; MESSAGE, D.; ALVES, M.L.T.M.F. First report in Brazil of Tyrophagus putrescentiae (Schrank) (Acari: Acaridae) in colonies of Africanized honey bees (Apis mellifera L.). Interciencia, v.39, p.742-744, 2014. 
TEIXEIRA, E.W.; SANTOS, L.G. dos; SATTLER, A.; MESSAGE, D.; ALVES, M.L.T.M.F.; MARTINS, M.F.; GRASSI-seLLA, M.L.; FRANCOY, T.M. Nosema ceranae has been present in Brazil for more than three decades infecting Africanized honey bees. Journal of Invertebrate Pathology, v.114, p.250-254, 2013. DOI: 10.1016/j.jip.2013.09.002.

TOKARZ, R.; FIRTH, C.; STREET, C.; COX-FOSTER, D.L.; LIPKIN, W.I. Lack of evidence for an association between Iridovirus and colony collapse disorder. Plos One, v.6, e21844, 2011. DOI: 10.1371/journal.pone.0021844.

TOMÉ, H.V.V.; BARBOSA, W.F.; MARTINS, G.F.; GUEDES, R.N.C. Spinosad in the native stingless bee Melipona quadrifasciata: regrettable non-target toxicity of a bioinsecticide. Chemosphere, v.124, p.103-109, 2015. DOI: 10.1016/j.chemosphere.2014.11.038.

VANDAME, R.; MORAND, S.; COLIN, M.-E.; BELZUNCES, L.P. Parasitism in the social bee Apis mellifera: quantifying costs and benefits of behavioral resistance to Varroa destructor mites. Apidologie, v.33, p.433-445, 2002. DOI: 10.1051/apido:2002025.

VANDAME, R.; PALACIO, M.A. Preserved honey bee health in Latin America: a fragile equilibrium due to low-intensity agriculture and beekeeping? Apidologie, v.41, p.243-255, 2010. DOI: 10.1051/apido/2010025.

vanENGELSDORP, D.; EVANS, J.D.; SAEGERMAN, C.; MULLIN, C.; HAUBRUGE, E.; NGUYEN, B.K.; FRAZIER, M.; FRAZIER, J.; COX-FOSTER, D.; CHEN, Y.; UNDERWOOD, R.; TARPY, D.R.; PETTIS, J.S. Colony collapse disorder: a descriptive study. Plos One, v.4, e6481, 2009. DOI: 10.1371/ journal.pone.0006481.

vanENGELSDORP, D.; HAYES JR., J.; UNDERWOOD, R.M.; CARON, D.; PETTIS, J. A survey of managed honey bee colony losses in the USA, fall 2009 to winter 2010. Journal of Apicultural Research, v.50, p.1-10, 2011. DOI: 10.3896/IBRA.1.50.1.01.

vanENGELSDORP, D.; HAYES JR., J.; UNDERWOOD, R.M.; PETTIS, J. A survey of honey bee colony losses in the U.S., fall 2007 to spring 2008. Plos One, v.3, e4071, 2008. DOI: 10.1371/ journal.pone.0004071.
vanENGELSDORP, D.; HAYES JR., J.; UNDERWOOD, R.M.; PETTIS, J.S. A survey of honey bee colony losses in the United States, fall 2008 to spring 2009. Journal of Apicultural Research, v.49, p.7-14, 2010. DOI: 10.3896/IBRA.1.49.1.03.

vanENGELSDORP, D.; UNDERWOOD, R.; CARON, D.; HAYES JR, J. An estimate of managed colony losses in the winter of 20062007: a report commissioned by the Apiary Inspectors of America. American Bee Journal, v.147, p.599-603, 2007.

VIDAL, M. de F. Efeitos da seca de 2012 sobre a apicultura nordestina. Informe Rural Etene, ano 7, p.1-5, 2013. Disponível em: <http://www.bnb.gov.br/documents/88765/89729/ire_ano7 n2.pdf/7a9e8843-0f57-4ed8-b737-0a6096c915cd>. Acesso em: $1 \overline{6}$ fev. 2016.

WORLD ORGANISATION FOR ANIMAL HEALTH. Official health control of bee diseases. Available at: $<\mathrm{http}: / / \mathrm{www} .0 i e$. int $/$ index.php? $\mathrm{id}=169 \& \mathrm{~L}=0 \&$ htmfile $=$ chapitre bee control.htm $>$. Accessed on: 28 Aug. 2015.

WHITEHORN, P.R.; O'CONNOR, S.; WACKERS, F.L.; GOULSON, D. Neonicotinoid pesticide reduces bumble bee colony growth and queen production. Science, v.336, p.351-352, 2012. DOI: $10.1126 /$ science. 1215025 .

WHITFIELD, C.W.; BAND, M.R.; BONALDO, M.F.; KUMAR, C.G.; LIU, L.; PARDINAS, J.R.; ROBERTSON, H.M.; BENTO SOARES, M.; ROBINSON, G.E. Annotated expressed sequence tags and cDNA microarray for studies of brain and behavior in the honey bee. Genome Research, v.12, p.555-566, 2002. DOI: $10.1101 /$ gr.5302.

YANG, E.C.; CHUANG, Y.C.; CHEN Y.L.; CHANG, L.H. Abnormal foraging behavior induced by sublethal dosage of imidacloprid in the honey bee (Hymenoptera: Apidae). Journal of Economic Entomology, v.101, p.1743-1748, 2008. DOI: 10.1603/0022-0493-101.6.1743.

ZHANG, G.; ZHANG, W.; CUI, W.; XU, B. Zinc nutrition increases the antioxidant defenses of honey bees. Entomologia Experimentalis et Applicata, v.156, p.201-210, 2015. DOI: 10.1111/eea.12342.

Recebido em 1 de outubro de 2015 e aprovado em 4 de março de 2016

Pesq. agropec. bras., Brasília, v.51, n.5, p.422-442, maio 2016

DOI: 10.1590/S0100-204X2016000500003 